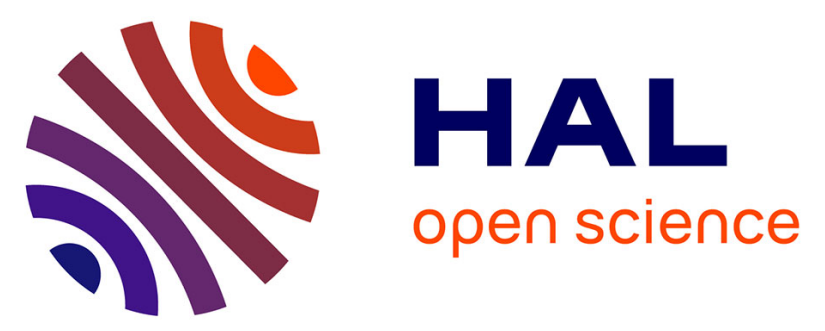

\title{
Inferring the dynamic of mutated hematopoietic stem and progenitor cells induced by $\operatorname{IFN} \alpha$ in myeloproliferative neoplasms
}

\author{
Matthieu Mosca, Gurvan Hermange, Amandine Tisserand, Robert John \\ Noble, Christophe Marzac, Caroline Marty, Cécile Le Sueur, Hugo Campario, \\ Gaëlle Vertenoeil, Mira El-Khoury, et al.
}

\section{To cite this version:}

Matthieu Mosca, Gurvan Hermange, Amandine Tisserand, Robert John Noble, Christophe Marzac, et al.. Inferring the dynamic of mutated hematopoietic stem and progenitor cells induced by IFN $\alpha$ in myeloproliferative neoplasms. Blood, 2021, 10.1182/blood.2021010986 . hal-03452002

\section{HAL Id: hal-03452002 \\ https://hal-centralesupelec.archives-ouvertes.fr/hal-03452002}

Submitted on 26 Nov 2021

HAL is a multi-disciplinary open access archive for the deposit and dissemination of scientific research documents, whether they are published or not. The documents may come from teaching and research institutions in France or abroad, or from public or private research centers.
L'archive ouverte pluridisciplinaire HAL, est destinée au dépôt et à la diffusion de documents scientifiques de niveau recherche, publiés ou non, émanant des établissements d'enseignement et de recherche français ou étrangers, des laboratoires publics ou privés. 


\title{
7. blood
}

American Society of Hematology

2021 L Street NW, Suite 900,

Washington, DC 20036

\section{Inferring the dynamic of mutated hematopoietic stem and progenitor cells induced by IFN $\alpha$ in myeloproliferative neoplasms}

\author{
Tracking no: BLD-2021-010986R3 - CORRECTION
}

Matthieu Mosca (Université Paris-Saclay, France) Gurvan Hermange (Université Paris-Saclay, France) Amandine Tisserand (Université de Paris, France) Robert Noble (City, University of London, United Kingdom) Christophe Marzac (INSERM, UMR 1287, France) Caroline Marty (Université Paris-Saclay, France) Cécile Le Sueur (Department of Biosciences and Engineering, ETH Zurich, Germany) Hugo Campario (Laboratoire d'hématologie, CHU Dijon, France) Gaëlle Vertenoeil (Ludwig Institute for Cancer Research Brussels, Belgium) Mira El-Khoury (INSERM, UMR 1287, France) Cyril Catelain (Plateforme d'Imagerie et Cytométrie, Gustave Roussy, France) Philippe Rameau (UMS AMMICa- Plate-forme Imagerie et Cytométries Gustave Roussy Cancer Campus, France) Cyril Gella (Gustave Roussy, France) Julien Lenglet (Hôpital privé d'Antony, France) Nicole Casadevall (INSERM, UMR 1287, France) Remi Favier (Assistance Publique Hôpitaux de Paris, France) Eric Solary (Université Paris-Saclay, Faculté de Médecine, Le KremlinBicêtre, France) Bruno Cassinat (INSERM UMRS 1131, IRSL, Hôpital Saint-Louis, France) Jean-Jacques Kiladjian (INSERM UMRS 1131, IRSL, Hôpital Saint-Louis, France) Stefan Constantinescu (Ludwig Institute for Cancer Research, Belgium) Florence Pasquier (INSERM, UMR 1287, France) Michael Hochberg (Santa Fe Institute, Santa Fe, United States) Hana Raslova (Université Paris-Saclay, France) Jean-Luc Villeval (Université Paris-Saclay, France) François Girodon (INSERM, UMR866, France) William Vainchenker (INSERM, UMR 1287, France) Paul-Henry Cournède (Université Paris-Saclay, CentraleSupélec, France) Isabelle Plo (Université Paris-Saclay, France)

\section{Abstract:}

Classical BCR-ABL-negative myeloproliferative neoplasms (MPN) are clonal disorders of hematopoietic stem cells (HSC) caused mainly by recurrent mutations in genes encoding JAK2 (JAK2), calreticulin (CALR), or the thrombopoietin receptor (MPL). Interferon alpha (IFNA) has demonstrated some efficacy in inducing molecular remission in MPN. In order to determine factors that influence molecular response rate, we evaluated the long-term molecular efficacy of IFNo in MPN patients by monitoring the fate of cells carrying driver mutations in a prospective observational and longitudinal study of 48 patients over more than 5 years. We measured several times per year the clonal architecture of early and late hematopoietic progenitors (84,845 measurements) and the global variant allele frequency in mature cells (409 measurements). Using mathematical modeling and hierarchical Bayesian inference, we further inferred the dynamics of IFN $\alpha$-targeted mutated HSC. Our data support the hypothesis that IFN $\alpha$ targets JAK2 $617 F$ HSC by inducing their exit from quiescence and differentiation into progenitors. Our observations indicate that treatment efficacy is higher in homozygous than heterozygous JAK2 ${ }^{\mathrm{V} 617 \mathrm{~F}}$ HSC and increases with high IFN $\alpha$ dosage in heterozygous JAK2 ${ }^{\mathrm{V} 617 F}$ HSC. Besides, we found that the molecular responses of CALR ${ }^{m}$ HSC to IFN $\alpha$ were heterogeneous, varying between type 1 and type 2 CALR ${ }^{m}$, and high dosage of IFNa correlates with worse outcomes. Together, our work indicates that the long-term molecular efficacy of IFN implies an HSC exhaustion mechanism and depends on both the driver mutation type and IFNa dosage.

Conflict of interest: COI declared - see note

COI notes: JJK is consultant at AOP orphan.

Preprint server: No;

Author contributions and disclosures: M.M and A.T. performed experiments, analyzed data and wrote the manuscript, G.H. and R.N. performed the mathematical model, analyzed the data and wrote the manuscript, C. Marz. performed NGS myeloid panel and CALR sizing, B.C. myeloid panel performed NGS, G.V. and M.E-K performed experiments and analyzed data, P.R. and C.C performed cytometry analysis, H.C., J.L., N.C., E.S, J.J.K., F.P., F.G. have followed patients and provided samples, C.L.S. contributed to the mathematical model and analyzed the data, S.N.C, C.Mart. H.R and J.L.V contributed to the research design; M.E.H contributed to the research design of the mathematical model, V.W followed patients, provided samples and contributed to the research design; P-H.C. supervised the study on the mathematical model, interpreted data, and wrote the paper. I.P. supervised the study, planned research, interpreted data, and wrote the paper; and all authors revised the manuscript 
Agreement to Share Publication-Related Data and Data Sharing Statement: email to the corresponding author: isabelle.plo@gustaveroussy.fr

Clinical trial registration information (if any): 


\section{Inferring the dynamics of mutated hematopoietic stem and progenitor cells induced by IFN $\alpha$ in myeloproliferative neoplasms}

Running title: Inferring the molecular response of MPN to IFN $\alpha$

Matthieu Mosca ${ }^{1,2,3,4^{*}}$, Gurvan Hermange ${ }^{3,5^{*}}$, Amandine Tisserand ${ }^{1,2,4,6^{*}}$, Robert Noble ${ }^{7,8,9,10^{*}}$, Christophe Marzac ${ }^{1,2,3,11}$, Caroline Marty ${ }^{1,2,3,4}$, Cécile Le Sueur ${ }^{7}$, Hugo Campario ${ }^{12}$, Gaëlle Vertenoeil $^{13}$, Mira El-Khoury ${ }^{1,2,4}$, Cyril Catelain ${ }^{14}$, Philippe Rameau ${ }^{14}$, Cyril Gella ${ }^{11}$, Julien Lenglet $^{15}$, Nicole Casadevall ${ }^{1,16}$, Rémi Favier ${ }^{17}$, Eric Solary ${ }^{1,2,18,19}$, Bruno Cassinat ${ }^{20,21}$, JeanJacques Kiladjian ${ }^{20,22}$, Stefan N. Constantinescu ${ }^{13}$, Florence Pasquier ${ }^{1,2,3,18}$, Michael E. Hochberg $^{8,23}$, Hana Raslova ${ }^{1,2,3}$, Jean-Luc Villeval ${ }^{1,2,3}$, François Girodon $^{12,24}$, William Vainchenker ${ }^{1,2,3,4,25}$, Paul-Henry Cournède ${ }^{3,5}$, Isabelle Plo ${ }^{1,2,3,4}$

1- INSERM, UMR 1287, Gustave Roussy, Villejuif, France

2- Gustave Roussy, Villejuif, France

3- Université Paris-Saclay, Gif-sur-Yvette, France

4- Laboratoire d'Excellence GR-Ex, Paris, France

5- CentraleSupélec, Lab MICS, Gif-sur-Yvette, France

6- Université de Paris, Paris, France

7- Department of Biosciences and Engineering, ETH Zurich, Basel, Switzerland

8- Institut des Sciences de l'Evolution, University of Montpellier, Montpellier, France

9 - IEU, University of Zurich, Zurich, Switzerland

10 - City, University of London, London, UK

11- Laboratoire d'immuno-hématologie, Gustave Roussy, Villejuif, France

12- Laboratoire d'hématologie, CHU Dijon, Dijon France

13- Ludwig Institute for Cancer Research, and Université Catholique de Louvain, de Duve Institute, Brussels, Belgium

14- UMS AMMICa- Plateforme Imagerie et Cytométries, Gustave Roussy, Villejuif France

15- Hôpital Privé d'Antony, Antony, France

16- Assistance Publique des Hôpitaux de Paris, Laboratoire d'Hématologie, Hôpital Saint Antoine, Paris, France 
17- Assistance Publique des Hôpitaux de Paris, Service d'Hématologie biologique, Hôpital d'Enfants Armand-Trousseau, Paris

18- Département d'hématologie, Gustave Roussy, France

19- Université Paris-Saclay, Faculté de Médecine, Le Kremlin-Bicêtre, France

20- Université de Paris, INSERM UMRS 1131, IRSL, Hôpital Saint-Louis, Paris, France

21- Assistance Publique des Hôpitaux de Paris, Laboratoire de Biologie Cellulaire, hôpital Saint-Louis, Paris, France

22- Assistance Publique des Hôpitaux de Paris, Centre d'Investigations Cliniques, Hôpital Saint-Louis, Paris, France

23- Santa Fe Institute, Santa Fe, NM 87501, USA

24- INSERM, UMR866, Centre de Recherche, Dijon, France

25- Assistance Publique des Hôpitaux de Paris, Service d'Immunopathologie Clinique, Polyclinique d'hématologie, Hôpital Saint Louis, Paris, France

* These authors have equally contributed to the work

Corresponding authors: Isabelle Plo UMR INSERM U1287, Gustave Roussy, 114 rue Edouard Vaillant, 94805 Villejuif, isabelle.plo@gustaveroussy.fr; Phone: +33 (0)1 421142 33. Fax: +33 (0)142115240.

Keywords : IFN $\alpha$, classical MPN, progenitors, HSC, JAK2 $2^{V 617 F}, C A L R^{m}$, mathematical model Words number: 4200 words

Abstract: 246 words

Figures: 6

Supplemental figures: 12

Supplemental Tables: 2

Online supplemental materials

\section{Key points:}

- IFN $\alpha$ targets more efficiently homozygous than heterozygous $J A K 2^{\mathrm{V} 617 \mathrm{~F}} \mathrm{HSPC}$

- Heterozygous $J A K 2^{\mathrm{V} 617 \mathrm{~F}} \mathrm{HSPC}$ are more rapidly depleted by high dosages than by low dosages of IFN $\alpha$

- IFN $\alpha$ preferentially targets type $2 C A L R^{m} \mathrm{HSPC}$ than type $1 C A L R^{m} \mathrm{HSPC}$ 


\section{Abstract (234 words)}

Classical $B C R$ - $A B L$-negative myeloproliferative neoplasms (MPN) are clonal disorders of hematopoietic stem cells (HSC) caused mainly by recurrent mutations in genes encoding JAK2 $(J A K 2)$, calreticulin $(C A L R)$, or the thrombopoietin receptor $(M P L)$. Interferon alpha (IFN $\alpha)$ has demonstrated some efficacy in inducing molecular remission in MPN. In order to determine factors that influence molecular response rate, we evaluated the long-term molecular efficacy of IFN $\alpha$ in MPN patients by monitoring the fate of cells carrying driver mutations in a prospective observational and longitudinal study of 48 patients over more than 5 years. We measured several times per year the clonal architecture of early and late hematopoietic progenitors $(84,845$ measurements) and the global variant allele frequency in mature cells (409 measurements). Using mathematical modeling and hierarchical Bayesian inference, we further inferred the dynamics of IFN $\alpha$-targeted mutated HSC. Our data support the hypothesis that IFN $\alpha$ targets $J A K 2^{\mathrm{V} 617 \mathrm{~F}}$ HSC by inducing their exit from quiescence and differentiation into progenitors. Our observations indicate that treatment efficacy is higher in homozygous than heterozygous $J A K 2^{\mathrm{V} 617 \mathrm{~F}}$ HSC and increases with high IFNa dosage in heterozygous $J A K 2^{\mathrm{V} 617 \mathrm{~F}}$ HSC. Besides, we found that the molecular responses of $C A L R^{m}$ HSC to IFN $\alpha$ were heterogeneous, varying between type 1 and type $2 C A L R^{m}$, and high dosage of IFN $\alpha$ correlates with worse outcomes. Together, our work indicates that the long-term molecular efficacy of IFN $\alpha$ implies an HSC exhaustion mechanism and depends on both the driver mutation type and IFN $\alpha$ dosage. 


\section{INTRODUCTION}

Classical $B C R-A B L$-negative myeloproliferative neoplasms (MPN), including polycythemia vera (PV), essential thrombocythemia (ET) and primary myelofibrosis (PMF), are clonal hematological malignancies in which one or several mature blood cell types are overproduced. These diseases favor thrombo-hemorrhagic events and may transform into secondary acute myeloid leukemia. MPN occurrence is mostly associated with gain-of-function somatic mutations in genes encoding $J A K 2\left(J A K 2^{V 617 F}\right)$, calreticulin $\left(C A L R^{m}\right.$; type $1 C A L R^{d e l 52}$ and type $\left.2 C A L R^{\text {ins } 5}\right)$, or the thrombopoietin receptor $\left(M P L^{m}\right)$ that occur in hematopoietic stem cells (HSC) ${ }^{1-4}$. Several additional somatic mutations involved in epigenetic regulation, splicing and transcription factors can modify disease phenotype ${ }^{5}$.

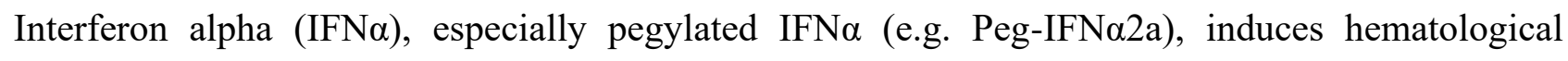
responses in ET, PV and some early $\mathrm{MF}^{6-10}$ as recently evidenced in a phase 2 clinical trial performed in hydroxyurea (HU)-refractory/intolerant patients with $J A K 2^{\mathrm{V} 617 \mathrm{~F}}$ and $C A L R^{m} \mathrm{MPN}^{11}$. Phase 3 randomized clinical trials demonstrated that another pegylated IFN, Ropeg-IFNa2b, increased the hematological response rate when compared to $\mathrm{HU}{ }^{12}$ or to phlebotomy ${ }^{13}$ in $\mathrm{PV}$ patients. Importantly, IFN $\alpha$, contrary to cytoreductive therapies or JAK inhibitors, is able to decrease the $J A K 2^{\mathrm{V} 617 \mathrm{~F}}$ variant allele frequency (VAF) in blood cells of about $60 \%$ of patients, including complete molecular responses in $20 \%$ of cases ${ }^{6,11,12}$, whereas its impact on $C A L R^{m}$ VAF is more debated ${ }^{11,14-16}$.

However, it remains unknown which factors impact the IFN $\alpha$-induced long-term molecular response rate. To unravel these determinants, we have performed a prospective longitudinal analysis of the long-term dynamics of $J A K 2^{\mathrm{V} 617 \mathrm{~F}}, C A L R^{m}$, and $M P L^{m}$ in hematopoietic stem and progenitor cells (HSPC) of MPN patients treated with IFNa. Over 5 years, we have collected a rich dataset from 48 patients in early and late progenitors together with the VAF in mature cells. Results from these investigations have permitted us to: i) investigate how IFN $\alpha$ targets HSPC differently according to mutation type, zygosity, and dosage, ii) build a mathematical model linked to a 
hierarchical Bayesian inference method that allows us to infer the dynamics of mutated HSC and their response to IFN $\alpha$ therapy.

\section{MATERIAL AND METHODS}

\section{Patients, cell purification and progenitor cultures}

Peripheral blood samples and bone marrow were collected from patients with their written informed consent in accordance with the Declaration of Helsinki and the study was approved by the Ethics Committee from CHU Dijon, Saint Louis Hospital and Gustave Roussy; from Comité de Protection des Personnes (CPP) Ile de France IV- Institutional review board (agreement from US Department of Health and Human Services ${ }^{\circ}$ IRB 00003835- Protocol 2015/59-NICB) and Commission Nationale de l'Informatique et des Libertés (CNIL) (authorization \#915663).

Mononuclear cells and granulocytes were purified by a Ficoll density gradient. Granulocytes were isolated and $\mathrm{CD}_{3}{ }^{+}$cells were purified by a double-positive magnetic cell sorting system (AutoMACS; Miltenyi Biotec). CD34 ${ }^{+}$cells were labeled with anti-CD90, -CD34 and -CD38 antibodies (Becton Dickinson) and both $\mathrm{CD}^{+} 0^{+} \mathrm{CD} 34^{+} \mathrm{CD} 38^{-}$, and $\mathrm{CD} 90^{-} \mathrm{CD} 34^{+} \mathrm{CD} 38^{-}$and $\mathrm{CD}^{-}$ $\mathrm{CD} 4^{+} \mathrm{CD} 38^{+}$cell fractions were sorted at 1 progenitor/well in 96-well plates with a BD Influx cell sorter. Clones were expanded in serum-free medium with a cocktail of human recombinant cytokines containing $1 \mathrm{U} / \mathrm{mL}$ EPO (Amgen), $20 \mathrm{ng} / \mathrm{mL}$ TPO (generous gift from Kirin), $10 \mathrm{ng} / \mathrm{mL}$ FLT3-L (Celldex Therapeutics), 10 ng/mL IL-3, 20 ng/mL G-CSF, 10 ng/mL IL-6 (Miltenyi Biotech), $25 \mathrm{ng} / \mathrm{mL}$ SCF and $5 \mu \mathrm{g} / \mathrm{mL}$ GM-CSF (Peprotech). Fourteen days later, individual colonies corresponding to the progeny of each progenitor were lysed and DNA was genotyped for homozygous, heterozygous or wild-type (wt) status as previously described ${ }^{1,15,17,18}$.

\section{Inclusion, response criteria, IFNa doses}

This prospective, longitudinal, observational study included 48 patients with ET, PV or MF diagnosis according to the 2016 iteration of the WHO classification ${ }^{19}$ with $J A K 2^{V 617 F}, C A L R^{m}$, or 
$M P L^{m}$. These patients were included and followed for at least three months after starting peg-IFN $\alpha$ therapy. Hematological response was assessed according to the European LeukemiaNet (ELN) criteria for ET and PV. Prior treatments with other cytoreductive drugs were not excluded.

As indicated in Figure 1A, we first determined the effect of genotype and dosage in progenitor and mature cells for the 48 patients. Second, to evaluate the IFN $\alpha$-induced dynamics of mutated HSC we used a mathematical model. Several inclusion criteria were used for the parameter estimation of the mathematical model and the statistical analyses. In our population-based hierarchical framework, even patients with few data points bring information to estimate the population parameters. Thus, to calibrate the model, we included 40 patients for which we have at least three data time points. However, the estimation of individual parameters for patients with few data points suffers from overfitting. Therefore, to conduct hypothesis testing between subpopulations (mutation type, dose) that relies on individual parameters, we excluded patients with fewer than five progenitor measurements for $J A K 2^{V 617 F}$ (mainly corresponding to intolerant patients). No further $C A L R^{m}$ patient was excluded because the model was less complex. Moreover, patients may carry heterozygous and/or homozygous subclones in different proportions. When we analyzed the impact of the zygosity on the response to IFNa and thus studied separately the homozygous and heterozygous subclones, as permitted by our model, it was necessary to exclude the data of patients whose subclones exhibited low clonal fraction $(\mathrm{CF})(<7 \%)$. In our cohort, most $C A L R^{m}$ patients carried only heterozygous mutated subclones (10/12 cases). For JAK2 ${ }^{\mathrm{V} 617 \mathrm{~F}}$ patients, we defined two overlapped subgroups: patients carrying sufficient proportion of heterozygous subclones (17 patients) or homozygous subclones (10 patients) with several patients harboring both (Figure 1B). Patients received variable peg-IFN $\alpha$ doses over their follow-up, i.e. dosages were commonly increased within the first months of therapy and then decreased after about 450 days (Figure 1C). Peg-IFN $\alpha$ dosages used throughout the article are averages computed over the first 450 days of therapy (Table S1). To test the dose-effect on the response, we divided patients into high (HD) and low dose (LD) groups according to whether the average dosage was above or below the median and 
performed Mann-Whitney U tests. To complement our analyses and avoid this binary distinction between HD and LD, we also considered the dosage as a continuous quantity, performed linear regressions (response factor against dosage), and tested the nullity of the linear regression coefficients.

\section{Mathematical model}

We extended the model of Michor et al. ${ }^{20}$ to infer the latent dynamics of the mutated stem cells targeted by IFN $\alpha$. Numbers of wild-type quiescent HSC, active HSC, progenitors and mature cells are respectively denoted $N_{1}, N_{2}, N_{i}$ and $N_{m}$. The corresponding mutated cell numbers are denoted $N_{h e t, 1}, N_{h e t, 2}, N_{h e t, i}$ and $N_{h e t, m}$ for heterozygous mutated cells and $N_{h o m, 1}, N_{h o m, 2}, N_{h o m, i}$ and $N_{h o m, m}$ for homozygous mutated cells. HSC become active at rate $\gamma$, and quiescent at rate $\beta$. These parameters are indexed with subscripts to distinguish wt, heterozygous or homozygous cells. Active HSC can be recruited for contributing to hematopoiesis with rate $\alpha$, and parameter $\Delta$ models the propensity of the stem pool to deplete (if $\Delta<0$ ) or to expand (if $\Delta>0$ ). Homeostatic conditions are achieved by setting $\Delta=0$. Progenitors originate from a stem cell that has undergone several divisions, modeled by clonal expansion parameter $\kappa_{\mathrm{i}}$. Progenitors exit their compartment at rate $\delta_{\mathrm{i}}$. Having undergone further clonal expansion (modeled by $\kappa_{\mathrm{m}}$ ), progenitors become mature cells that die at rate $\delta_{\mathrm{m}}$. The basic mathematical model is given by:

$$
\left\{\begin{array}{l}
\dot{N}_{1}=-\gamma N_{1}+\beta N_{2} \\
\dot{N}_{2}=\gamma N_{1}+(\alpha \Delta-\beta) N_{2} \\
\dot{N}_{i}=\alpha(1-\Delta) \kappa_{i} N_{2}-\delta_{i} N_{i} \\
\dot{N}_{m}=\delta_{i} \kappa_{m} N_{i}-\delta_{m} N_{m}
\end{array}\right.
$$

From the absolute numbers of cells, we obtain corresponding clonal fractions by normalisation. We assume that IFN $\alpha$ modifies some parameter values after the start of the therapy. These modified parameters are marked with an asterisk $(*)$.

\section{Statistical inference method}


We distinguish three populations of patients based on their disease mutation $\left(J A K 2^{\mathrm{V} 617 \mathrm{~F}}, C A L R^{m}\right.$ or $\left.M P L^{m}\right)$. Within each population, we estimate patient-specific parameters using a Bayesian hierarchical framework. This population-based approach adds robustness to the results and reduces overfitting. We provide more details about the inference models and their validation in the supplementary online methods.

\section{RESULTS}

\section{Study of MPN prospective cohort treated with IFNa}

In a prospective observational study performed over 5 years, we included 48 MPN patients and analyzed their blood samples either before and during IFN $\alpha$ treatment or only during treatment (Table S1). This cohort includes 21 PV (44\%), 22 ET (46\%) and 5 PMF (10\%). We detected 32 MPN patients with $J A K 2^{\mathrm{V} 617 \mathrm{~F}}, 12$ with $C A L R^{m}$ (7 type 1 and 5 type 2), 2 with $M P L^{W 515 K / R}$, one having both $J A K 2^{\mathrm{V} 617 \mathrm{~F}}$ and $C A L R^{d e l 46}$ and one having $J A K 2^{\mathrm{V} 617 \mathrm{~F}}, C A L R^{\text {del52 }}$ and $M P L^{\mathrm{S} 505 \mathrm{~N}}$ (Figure $2 \mathrm{~A}$ and $\mathrm{B})$. We classified the last two cases as $C A L R^{m} \mathrm{MPN}$ because the $C A L R^{m} \mathrm{VAF}>0.4$ were clearly dominant ${ }^{21}$ and because the $J A K 2^{\mathrm{V} 617 \mathrm{~F}}$ and $C A L R^{\mathrm{m}}$ were mutually exclusive in progenitors (Figure S1). Next generation sequencing of a myeloid-focused panel of 77 genes using genomic DNA isolated from granulocytes identified additional mutations in 31\% of these cases (Figure 2C). The median age before treatment was 53 years [range 25-71]. The median dose was $71 \mu \mathrm{g} / \mathrm{week}$ [range 11-157]. Hematological response was observed in $78 \%$ of $J A K 2^{\mathrm{V} 617 \mathrm{~F}}, 72 \%$ of $C A L R^{m}$ and in the $2 M P L^{m}$ cases. Side effects leading to treatment discontinuation were observed in $16 \%$ and $21 \%$ of patients having $J A K 2^{\mathrm{V} 617 \mathrm{~F}}$ and $C A L R^{m} \mathrm{MPN}$, respectively. We found 6-7\% hematological nonresponders in both $J A K 2^{\mathrm{V} 617 \mathrm{~F}}$ and $C A L R^{m}$ cases (Figure 2D).

IFNa targets hematopoietic progenitors differently according to mutation type, zygosity and dosage 
Samples were collected longitudinally several times per year and five different cell populations were purified from the peripheral blood for each time point. These cell populations included mature cells (granulocytes and platelets) and different types of progenitors including HSC-enriched progenitors $\left(\mathrm{CD} 90^{+} \mathrm{CD} 34^{+} \mathrm{CD} 38^{-}\right)$, immature progenitors $\left(\mathrm{CD} 90^{-} \mathrm{CD} 34^{+} \mathrm{CD} 38^{-}\right)$, and committed progenitors $\left(\mathrm{CD} 90^{-} \mathrm{CD} 34^{+} \mathrm{CD} 38^{+}\right)$. On the one hand, we performed the global allele burden in granulocytes (409 measures), in platelets (102 measures) and in CD34 ${ }^{+}$progenitors (175 measures). We observed that, at a given time point, the $J A K 2^{V 617 F}$ VAF correlated in platelets and granulocytes and was similar among all progenitor types (Figure S2). On the other hand, we performed singlecell colony assay using progenitors for 395 time points. The median number of genotyped progenitor-derived colonies was 226 per time point and the median clonogenicities were $67 \%, 71 \%$ and $79 \%$ for $\mathrm{CD} 0^{+} \mathrm{CD} 34^{+} \mathrm{CD} 38^{-}, \mathrm{CD} 90^{-} \mathrm{CD} 34^{+} \mathrm{CD} 38^{-}$and $\mathrm{CD}^{-} 0^{-} \mathrm{CD} 34^{+} \mathrm{CD} 38^{+}$, respectively. Altogether, we analyzed the genotypes of 84,845 progenitor-derived colonies for the whole cohort (Figure S3 A-D). We observed a significant correlation between the VAF measured from the genotype of progenitor-derived colonies and from the $\mathrm{CD} 34^{+}$progenitor bulk (Figure S2). For two patients, we observed a very close $J A K 2^{V 617 F}$ VAF in progenitors and in granulocytes both in the bone marrow and peripheral blood, at a given time point (Figure S3E).

Using the VAF from the experimental data in granulocytes and progenitors, we monitored the dynamics of $J A K 2^{\mathrm{V} 617 \mathrm{~F}}, C A L R^{m}$ and $M P L^{m}$ cells during IFN $\alpha$ treatment in the 48 patients. While $C A L R^{m}$ VAF remained stable during treatment, the $J A K 2^{\mathrm{V} 617 \mathrm{~F}} \mathrm{VAF}$ decreased over time in both mature hematopoietic cells and progenitors. $C A L R^{m}$ and $J A K 2^{\mathrm{V} 617 \mathrm{~F}}$ VAF became substantially different after 600 days of treatment. The two $M P L^{m}$ cases demonstrated a clear molecular response over time (Figures 3 and S4).

We investigated whether the dynamics of $J A K 2^{\mathrm{V} 617 \mathrm{~F}}$ and $C A L R^{\mathrm{m}}$ progenitors vary with different IFN $\alpha$ dosages. While we did not detect any significant effect of IFN $\alpha$ dosage on $C A L R^{\mathrm{m}}$ progenitors (Figure 3Bi), JAK2 $2^{\mathrm{V} 617 \mathrm{~F}} \mathrm{VAF}$ decreased in progenitors with a better response upon high dosages detected from day 1,000 (Figure 3Bii). Typically, in some individuals with $J A K 2^{\mathrm{V} 617 \mathrm{~F}}$ MPN treated 
with high IFN $\alpha$ dosages, we observed an increase in the $J A K 2^{\mathrm{V} 617 \mathrm{~F}} \mathrm{VAF}$ at the beginning of treatment followed by a substantial decrease as well as spikes in total numbers of progenitor cells, granulocytes and platelets (bell curves) (Figure S4). In contrast, a progressive and continuous VAF decrease was seen in patients treated with low IFNa dosages. Finally, progenitors carrying homozygous $J A K 2^{\mathrm{V} 617 \mathrm{~F}}$ were significantly more sensitive to IFN $\alpha$ than those carrying heterozygous $J A K 2^{\mathrm{V} 617 \mathrm{~F}}$ starting from 600 days of treatment (Figure 3Biii).

In aggregate, these results identify a slow clearing of $J A K 2^{\mathrm{V} 617 \mathrm{~F}}$ progenitors over time in IFN $\alpha$ treated patients while $C A L R^{m}$ progenitors are less responsive on average. Moreover, IFN $\alpha$ targets $J A K 2^{\mathrm{V} 617 \mathrm{~F}}$ progenitors faster at high dosages and is more efficient against homozygous than heterozygous cells.

\section{Inferring IFNo-induced dynamics of mutated HSC using mathematical and statistical modeling}

Potential weaknesses in the analysis of experimental data are a lack of pre-treatment evaluation in several patients and the heterogeneity within the most purified HSC fraction (here $\mathrm{CD}_{3} 4^{+} \mathrm{CD} 38^{-}$ $\mathrm{CD}^{+}{ }^{+}$). To precisely characterize IFN $\alpha$-induced dynamics of mutated HSC, progenitors and mature cells, and to infer long-term treatment effects on mutated HSC, we designed a compartmental mathematical model ${ }^{20}$ (Figure 4A). This model was used as a rigorous mathematical framework to leverage information from our data. It is based on the hypothesis that IFN $\alpha$ induces latent and unobserved HSC dynamics that impact progenitor cells and granulocytes ${ }^{22}$. Cell populations were divided into compartments according to genotype and maturity: inactive HSC (compartment 1) or active HSC (compartment 2) that can generate differentiated progenitors (compartment $i$ ) that in turn will give rise to mature cells (compartment $m$ ). This type of model with two HSC compartments could explain the bell curves observed upon IFN $\alpha$ treatment in several $J A K 2^{V 617 F}$ patients. The model potentially includes many patient-specific parameters that can lead to risks of overfitting and non-identifiability. Since it is particularly challenging to infer the parameter values 
of human HSC, we made several hypotheses (Table S2). Since chronic, in contrast to acute IFN $\alpha$ exposure, induces transient proliferation of mouse HSC followed by a rapid return to quiescence ${ }^{23-}$ ${ }^{25}$, we assumed that IFN $\alpha$ barely influences the parameters of wt human HSC. In addition, we simplified the model to one HSC compartment in $C A L R^{m}$ patients in order to avoid overfitting based on reports showing a high clonal advantage of mutated $C A L R^{m}$ in the HSPC compartment compared to the $J A K 2^{V 617 F}$ HSC, suggesting that $C A L R^{m}$ HSC are more active ${ }^{18,26}$.

We calibrated the model based on the data of $27 J A K 2^{\mathrm{V} 617 \mathrm{~F}}, 12 C A L R^{m}$, and $1 M P L^{m}$ cases and chose a hierarchical Bayesian framework to increase robustness. Assuming that patients with the same driver mutation would have comparable parameter values, we considered three independent subpopulations, i.e. three independent parameter distributions in the hierarchical framework (Figure S5). With relatively few degrees of freedom, our simple model can fit the longitudinal molecular data (Figure S6) and describe $J A K 2^{\mathrm{V} 617 \mathrm{~F}}, C A L R^{m}$, and $M P L^{m}$ progenitor and mature cell dynamics in patients for up to 3,000 days of treatment (Figures 4B and S7-9).

This model-based approach enabled us to infer the effects of IFN $\alpha$ on mutated HSC depending on mutation type and zygosity. We inferred rapid depletion of homozygous JAK2 $2^{V 617 F}$ HSC, concomitant in some cases with an initial rapid increase followed by a drastic decrease in both the homozygous $J A K 2^{V 617 F}$ progenitor population and the $J A K 2^{V 617 F}$ granulocytes (Figure 4Bi). Among heterozygous $J A K 2^{V 617 F}$ cells, we inferred slow and simultaneous depletion of HSC, progenitors and granulocytes (Figure 4Bii). The dynamics of $C A L R^{m}$ cells (10/12 patients had no homozygous subclones) were more heterogenous, with a slow depletion in the patients presenting a molecular response (Figure 4Biii). Finally, we deduced a rapid depletion of heterozygous $M P L^{m}$ HSC (Figure 4Biv).

In summary, the inferred latent HSC dynamics accord with our observations in progenitors and mature cells, and our data support our working hypothesis that IFN $\alpha$ is acting on mutated HSC.

\section{HSC are targeted differently according to mutation type, zygosity and IFN $\alpha$ dosages}


Most patients with $C A L R^{m}$ in our cohort have heterozygous mutated cells. Therefore, we quantified the long-term heterozygous molecular response in HSC after 3,000 days by estimating the R factor (Response factor), defined as the mutated HSC proportion (or clonal fraction CF) relative to its initial value. We observed a heterogeneous molecular response in $C A L R^{m} \mathrm{HSC}$, such that higher IFN $\alpha$ dosages correlated with a poorer HSC response (Figures 5Ai and S11i). Even though few patients were analyzed, type $2 C A L R^{m}$ HSC were targeted more effectively than type $1 C A L R^{m} \mathrm{HSC}$ (Figures 5Aii).

In contrast, we observed a molecular response in most HSC from $J A K 2^{\mathrm{V} 617 \mathrm{~F}}$ patients, with an $\mathrm{R}$ factor significantly better for homozygous than for heterozygous HSC (Figure 5Aiii). There was an improved response of heterozygous $J A K 2^{\mathrm{V} 617 \mathrm{~F}}$ HSC upon treatment with high dosages of IFN $\alpha$ $(\mathrm{P}=0.0745$ with the Mann-Whitney $\mathrm{U}$ test; $\mathrm{P}=0.0498$ when testing the nullity of the linear regression coefficient) (Figure 5Aiv), but no strong dosage effect on the response of homozygous HSCs (Figure 5Av). When analyzing the global $J A K 2^{\mathrm{V} 617 \mathrm{~F}} \mathrm{VAF}$, patients treated with high IFN $\alpha$ dosages responded the best (Figure 5Avi). In addition, we observed a clear tendency for better responses while continuously increasing the dosages (Figure S11ii, iv).

We next inferred the median time to achieve a 50\% reduction of R factor (PMR) in mutated HSC. Homozygous $J A K 2^{V 617 F}$ HSC were depleted faster than heterozygous $J A K 2^{V 617 F}$ HSC in responding patients (350 days versus 920 days, respectively) (Figure S11Bi). The IFN $\alpha$ dosage significantly reduced the PMR in heterozygous HSC (Figure S11Bii), but not in homozygous HSC (Figure S11Biii). In comparison, while receiving a low dosage of IFN $\alpha$, we estimated that $M P L^{m}$ and type 2 CALR patients reached the PMR approximately at 600 days (Figure S11iv).

In patients with predominantly $J A K 2^{\mathrm{V} 617 \mathrm{~F}}$ cells, we found no evidence that the disease type (PV or ET), patient age at treatment initiation, sex, or the presence of associated mutations influence the mutated stem cell dynamics (Table S1). 
In conclusion, we inferred that the molecular response at the HSC level induced by IFN $\alpha$ is dependent on the type of mutation $\left(J A K 2^{\mathrm{V} 617 \mathrm{~F}}\right.$, type $\left.1 / 2 C A L R^{m}\right), J A K 2^{\mathrm{V} 617 \mathrm{~F}}$ zygosity, and IFN $\alpha$ dosage.

\section{IFNa differentially impacts on $J A K 2^{\mathrm{V} 617 \mathrm{~F}}$ and $C A L R^{m}$ HSC homeostasis}

The mathematical model built to describe the dynamics of HSPC also aims to provide insights on IFN $\alpha$ mechanism of action. The two critical parameters introduced in the model to describe IFN $\alpha$ effects are $\Delta^{*}$ and $\gamma^{*} \Delta^{*}$ het and $\gamma^{*}$ het for heterozygous cells and $\Delta^{*}$ hom and $\gamma^{*}$ hom for homozygous cells. The first parameter $\Delta^{*}$ indicates the self-renewal divisions of mutated HSCs under IFN $\alpha$ and becomes negative if divisions generate more differentiated cells, eventually leading to HSC exhaustion. The second parameter $\gamma^{*}$ describes the rate at which quiescent mutated HSC become active. An increase of $\gamma^{*}$ means that more mutated HSC are active and available to contribute to hematopoiesis.

In patients with $J A K 2^{\mathrm{V} 617 \mathrm{~F}} \mathrm{MPN}$, we estimated that IFN $\alpha$ induces negative values for $\Delta_{\text {het }}^{*}$ and $\Delta^{*}$ hom $(-0.20$ and -0.29 , respectively) (Figures 6Ai and S12i), indicating - according to our modeling - that IFN $\alpha$ would promote differentiating divisions of mutated HSCs leading to the exhaustion of that compartment. The $\Delta^{*}$ values were found to differ significantly between patients with $J A K 2^{\mathrm{V} 617 \mathrm{~F}}$ MPN and those with $C A L R^{m}$ MPN, suggesting a mechanism of action of IFN $\alpha$ relying on $J A K 2^{\mathrm{V} 617 \mathrm{~F}}$ HSC depletion (Figures 6Ai and S12i, iii). Nevertheless, the estimated $\Delta^{*}$ values of type $2 C A L R^{m}$ HSC were significantly reduced compared to type $1 C A L R^{m}$ HSC (Figure 6Aii). Finally, IFNa would promote more exit from quiescence of homozygous $J A K 2^{V 617 F}$ HSC compared to heterozygous $J A K 2^{V 617 F}$ HSC, as indicated by the estimated $\gamma^{*}$ values (Figures 6Aiii and S12ii).

Altogether, we inferred that IFN $\alpha$ leads to $J A K 2^{\mathrm{V} 617 \mathrm{~F}}$ and type $2 C A L R^{m}$ HSC depletion by decreasing their tendency to self-renew. Moreover, IFN $\alpha$ would increase the exit of homozygous $J A K 2^{\mathrm{V} 617 \mathrm{~F}} \mathrm{HSC}$ from quiescence. 


\section{DISCUSSION}

This prospective, longitudinal analysis of MPN patients treated with IFNa over a 5-year period generates a rich dataset that, combined with mathematical modeling and hierarchical Bayesian inference, identifies the differential molecular responses of $J A K 2^{\mathrm{V} 617 \mathrm{~F}}, M P L^{m}$ and $C A L R^{m}$ MPN.

As previously reported from clinics, we observed high hematological response rates in MPN regardless of the type of disease type and driver mutation ${ }^{6-10}$. The global molecular response in granulocytes presented a decrease in VAF for $J A K 2^{\mathrm{V} 617 \mathrm{~F}} \mathrm{MPN}$ in agreement with the literature 6,7,11,12. Moreover, our results confirm the heterogeneity in molecular responses of $C A L R^{m} \mathrm{MPN}$. Overall, $C A L R^{m}$ MPN are less likely than $J A K 2^{\mathrm{V} 617 \mathrm{~F}}$ MPN to exhibit a molecular response in mature cells ${ }^{11,14-16,27,28}$. We also investigated the dynamics of HSPC targeted by IFN $\alpha$ in unprecedented detail and generally observed better molecular responses in $J A K 2^{V 617 F}$ than in $C A L R^{m}$ progenitors. These results contrast with the enhanced hematological response to IFN $\alpha$ and longer survival of $C A L R^{m}$ than $J A K 2^{V 617 F}$ patients in several studies ${ }^{11,27,29}$, potentially because IFN $\alpha$ has a general deleterious effect during megakaryopoiesis, which limits thrombocytosis in a disease restricted to the megakaryocytic lineage ${ }^{30}$.

The proposed mathematical model combined with statistical inference methods was proven to not only fit the experimental data for progenitors and mature cells but also infer long-term molecular responses in patients rarely sampled. It further enables us to characterize HSC dynamics that are inaccessible by direct cell isolation as the $\mathrm{CD} 90^{+} \mathrm{CD} 34^{+} \mathrm{CD} 38^{-}$cell fraction remains heterogeneous and would require single cell "omics" experiments to be finely characterized. With this model, we have gained insights into the molecular effects of IFN $\alpha$ on progenitors and diseaseinitiating HSC according to the type of driver mutation and IFN $\alpha$ dosage. We found that IFN $\alpha$ targets efficiently most $J A K 2^{V 617 F} \mathrm{HSC}$, and preferentially homozygous $J A K 2^{V 617 F}$ HSC, in agreement with our previous data for mature cells ${ }^{31}$. Although there are few patients, our results suggest that IFN $\alpha$ preferentially targets type $2 C A L R^{m}$ than type $1 C A L R^{m}$ HSC. Moreover, high 
dosages of IFN $\alpha$ were more effective than low dosages in targeting heterozygous $J A K 2^{V 617 F}$ HSC. In heterozygous $C A L R^{m}$ HSC, higher IFNa dosages correlated with a poorer response. This correlation could be due to poor hematological response that led to increasing the IFN $\alpha$ dosage by the treating physicians. There is at present no evidence to support high-dose IFN $\alpha$ treatment to achieve long-term molecular response in $C A L R^{m}$ patients. The model will need to be improved to account more precisely for time-varying treatment schedules. Interestingly, for $J A K 2^{\mathrm{V} 617 \mathrm{~F}}$ patients, not the type of disease, nor age, nor the number of associated mutations $(1,2$ or 3$)$ at the beginning of the treatment impacted the HSC dynamics. Nevertheless, we note that our study has limited power to detect effects of mutations in TET2, DNMT3A, or TP53 $3^{7}$ because very few patients in our cohort presented such mutations. Our ability to infer effects of genetic polymorphisms involved in the response to IFN $\alpha$, such as IFNL4, is limited by their moderate effect sizes ${ }^{32}$.

The mechanisms by which IFN $\alpha$ specifically targets $J A K 2^{\mathrm{V} 617 \mathrm{~F}}$ or $C A L R^{m}$ cells are still largely unknown. By combining mathematical modeling and Bayesian inference, we inferred that IFNa slowly depletes homozygous and heterozygous $J A K 2^{V 617 F}$ HSC with half-lives of approximately 12 and 31 months, respectively. Based on an independent cohort of similar size to ours, Pedersen et al. recently reported that, in responders to IFN $\alpha$ treatment, JAK2 ${ }^{V 617 F} \mathrm{VAF}$ decreased in granulocytes with a typical half-life between one and two years. They also observed that an initial increase in mutated granulocytes preceded the fastest rates of decrease ${ }^{33}$ as we also observed in several patients a temporary increase in the frequency of $J A K 2^{V 617 F}$ homozygous progenitors followed by a decrease. Thus, a VAF increase at the beginning of the treatment is not necessarily associated with a pejorative long-term molecular response. These results also fit well with a previously observed increase in progenitors in the bone marrow of $J A K 2^{V 617 F}$ patients shortly after IFN $\alpha$ treatment ${ }^{34}$. The experimental dynamics are consistent with a mathematical model in which the treatment exhausts heterozygous and homozygous $J A K 2^{V 617 F}$ HSC by promoting their exit from quiescence and differentiation into progenitors. Moreover, we inferred that IFN $\alpha$ depletes homozygous $J A K 2^{V 617 F}$ HSC by differentiation much more effectively than heterozygous $J A K 2^{V 617 F}$ 
HSC. Although its effect on $C A L R^{m}$ HSC is weaker, IFN $\alpha$ depletes type 2 more than type $1 C A L R^{m}$ HSC. The treatment would also preferentially favor the exit from quiescence of homozygous $J A K 2^{V 617 F}$ HSC. Similarly, in the $J A K 2^{\mathrm{V} 617 \mathrm{~F}}$ mouse model, IFN $\alpha$ has been shown to enhance mutated HSC proliferation and exit from quiescence, resulting in an increase in total number of progenitors ${ }^{22,35,36}$. Although the main mechanism of IFN $\alpha$ inferred by the mathematical model is HSC exhaustion by differentiation for both $J A K 2^{\mathrm{V} 617 \mathrm{~F}}$ and type $2 C A L R^{m}$ HSC, several other mechanisms might be considered. In contrast to our dynamic study, Tong et al. found, at one time point after IFN $\alpha$ treatment using Target-Seq, an increased quiescence in homozygous and apoptosis in heterozygous $J A K 2^{V 617 F}$ HSPC $^{38}$. It is possible that such pathways could be found in the remaining non targeted $J A K 2^{V 617 F} \mathrm{HSPC}$ at later time point or that several mechanisms such as senescence or apoptosis might cooperate to reinforce the HSC exhaustion ${ }^{34,35,37-39}$. Characterizing such additional factors will require more experimental data coupled with a more sophisticated model. It would also be essential to address the exact signaling mechanism of HSC depletion upon IFN $\alpha$. ROS increase, P53 and STAT1 overactivation as well as a specific priming of IFN $\alpha$ signaling have been reported with $J A K 2^{\mathrm{V} 617 \mathrm{~F} 35}$ but not with $C A L R^{m}{ }^{16}$. In contrast, $\mathrm{CALR}^{\mathrm{m}}$ but not JAK2 $2^{\mathrm{V} 617 \mathrm{~F}}$ is secreted and might deregulate the immune response induced by IFN $\alpha^{40}$. Our study also suggests that the weakest molecular responders are the type $1 C A L R^{m} \mathrm{HSC}$, potentially because this type of mutation deregulates specific signaling pathways that lead to a stronger amplification at the HSC level compared to type 2 CALR $R^{m 18,41}$.

Current administration of IFN $\alpha$ in clinical practice is neither standardized nor tailored to the causal mutation. Treatment strategies are guided primarily by hematological response and tolerability. Our work indicates that the efficacy of IFN $\alpha$ exhausting mutated HSC depends on the driver mutation type in HSC. Moreover, it suggests that dose titration to maximally tolerated dose may be more likely to achieve reduction in $J A K 2^{\mathrm{V} 617 \mathrm{~F}} \mathrm{HSC}$ and therefore attain hematologic response. Therefore, the dose intensity should be ideally maintained over treatment. Altogether, this 
study will open new avenues of research aiming to understand the precise differential effects of $J A K 2^{\mathrm{V} 617 \mathrm{~F}}$ and $C A L R^{m}$ on MPN initiating HSC.

\section{Acknowledgments}

We thank the cytometry platform of Gustave Roussy (Y. Lecluse). We acknowledge the patients that have accepted to participate to this biological protocol and the nurses for providing the samples. We also thank all trainees that contribute to the work. We thank E. Leclercq and MH Courtier for the technical assistance in CALR sizing. This work was supported by grants from MPN Research Foundation, INCA Plbio2014, INCA Plbio2018 to IP and JLV, Ligue Nationale Contre le Cancer (for HR, équipe labellelisée 2019). IP and PHC are granted by the Prism project, funded by the Agence Nationale de la Recherche under grant number ANR-18-IBHU-0002. Labex GR-Ex (IP, $\mathrm{JJK}$ ) is funded by the program "Investissements d'avenir". MM was supported by Ph.D grants from la ligue Nationale Contre le Cancer, Société Française d'Hématologie (SFH) and Gustave Roussy Foundation. MEK by the SFH, AT by a MENRT grant and GV by FNRS fellowship.

RN acknowledges support from ERC Synergy Grant 609883 and the National Cancer Institute of the National Institutes of Health under Award Number U54CA217376. The content is solely the responsibility of the authors and does not necessarily represent the official views of the National Institutes of Health. This manuscript was edited at Life Science Editors.

\section{Conflict-of-interest disclosure:}

The authors declare no competing financial interests. JJK is consultant at AOP orphan.

\section{Contribution:}

Contribution: M.M and A.T. performed experiments, analyzed data and wrote the manuscript, G.H. and R.N. performed the mathematical model, analyzed the data and wrote the manuscript, C. Marz. and C.G. performed NGS myeloid panel and CALR sizing, B.C. myeloid panel performed NGS, 
G.V. and M.E-K performed experiments and analyzed data, P.R. and C.C performed cytometry analysis, H.C., J.L., N.C., E.S, J.J.K., F.P., F.G., R.F., have followed patients and provided samples, C.L.S. contributed to the mathematical model and analyzed the data, S.N.C, C.Mart. H.R and J.L.V contributed to the research design; M.E.H contributed to the research design of the mathematical model, V.W followed patients, provided samples and contributed to the research design; P-H.C. supervised the study on the mathematical model, interpreted data, and wrote the paper. I.P. supervised the study, planned research, interpreted data, and wrote the paper; and all authors revised the manuscript

\section{REFERENCES}

1. James C, Ugo V, Le Couedic JP, et al. A unique clonal JAK2 mutation leading to constitutive signalling causes polycythaemia vera. Nature. 2005;434(7037):1144-8.

2. Pikman Y, Lee BH, Mercher T, et al. MPLW515L is a novel somatic activating mutation in myelofibrosis with myeloid metaplasia. PLoS medicine. 2006;3(7):e270.

3. Nangalia J, Massie CE, Baxter EJ, et al. Somatic CALR mutations in myeloproliferative neoplasms with nonmutated JAK2. N Engl J Med. 2013;369(25):2391-405.

4. Klampfl T, Gisslinger H, Harutyunyan AS, et al. Somatic mutations of calreticulin in myeloproliferative neoplasms. N Engl J Med. 2013;369(25):2379-90.

5. Vainchenker W, Kralovics R. Genetic basis and molecular pathophysiology of classical myeloproliferative neoplasms. Blood. 2017;129(6):667-679.

6. Kiladjian JJ, Cassinat B, Chevret S, et al. Pegylated interferon-alfa-2a induces complete hematologic and molecular responses with low toxicity in polycythemia vera. Blood. 2008;112(8):3065-72.

7. Quintas-Cardama A, Abdel-Wahab O, Manshouri T, et al. Molecular analysis of patients with polycythemia vera or essential thrombocythemia receiving pegylated interferon alpha-2a. Blood. 2013;

8. Stauffer Larsen T, Iversen KF, Hansen E, et al. Long term molecular responses in a cohort of Danish patients with essential thrombocythemia, polycythemia vera and myelofibrosis treated with recombinant interferon alpha. Leukemia Research. 2013;37(9):1041-1045.

9. Masarova L, Yin CC, Cortes JE, et al. Histomorphological responses after therapy with pegylated interferon alpha-2a in patients with essential thrombocythemia (ET) and polycythemia vera (PV). Experimental hematology \& oncology. 2017;6:30.

10. Silver RT. Recombinant interferon-alpha for treatment of polycythaemia vera. Lancet. 1988;2(8607):403.

11. Yacoub A, Mascarenhas J, Kosiorek H, et al. Pegylated interferon alfa-2a for polycythemia vera or essential thrombocythemia resistant or intolerant to hydroxyurea. Blood. 2019;134(18):1498-1509.

12. Gisslinger H, Klade C, Georgiev $\mathrm{P}$, et al. Ropeginterferon alfa-2b versus standard therapy for polycythaemia vera (PROUD-PV and CONTINUATION-PV): a randomised, non-inferiority, phase 3 trial and its extension study. The Lancet. Haematology. 2020;7(3):e196-e208. 
13. Barbui T, Vannucchi A, De Stefano V, et al. Phase II randomized clinical trial comparing ropeginterferon versus phlebotomy Iin low-risk patients with polycythemia vera. Results of the preplannes interim analysis. (LB2602). 2020;

14. Verger E, Cassinat B, Chauveau A, et al. Clinical and molecular response to interferonalpha therapy in essential thrombocythemia patients with CALR mutations. Blood. 2015;126(24):2585-91.

15. Kjaer L, Cordua S, Holmstrom MO, et al. Differential Dynamics of CALR Mutant Allele Burden in Myeloproliferative Neoplasms during Interferon Alfa Treatment. PloS one.

2016;11(10):e0165336.

16. Czech J, Cordua S, Weinbergerova B, et al. JAK2V617F but not CALR mutations confer increased molecular responses to interferon- $\alpha$ via JAK1/STAT1 activation. Leukemia. 2019;33(4):995-1010.

17. Chaligne R, James C, Tonetti C, et al. Evidence for MPL W515L/K mutations in hematopoietic stem cells in primitive myelofibrosis. Blood. 2007;110(10):3735-43.

18. El-Khoury M, Cabagnols X, Mosca M, et al. Different impact of calreticulin mutations on human hematopoiesis in myeloproliferative neoplasms. Oncogene. 2020;39(31):5323-5337.

19. Arber DA, Orazi A, Hasserjian R, et al. The 2016 revision to the World Health Organization classification of myeloid neoplasms and acute leukemia. Blood. 2016;127(20):2391405.

20. Michor F, Hughes TP, Iwasa Y, et al. Dynamics of chronic myeloid leukaemia. Nature. 2005;435(7046):1267-70.

21. Campario H, Mosca M, Aral B, et al. Impact of interferon on a triple positive polycythemia vera. Leukemia. 2020;34(4):1210-1212.

22. Mullally A, Bruedigam C, Poveromo L, et al. Depletion of Jak2V617F myeloproliferative neoplasm-propagating stem cells by interferon-alpha in a murine model of polycythemia vera. Blood. 2013;121(18):3692-702.

23. Pietras EM, Lakshminarasimhan R, Techner JM, et al. Re-entry into quiescence protects hematopoietic stem cells from the killing effect of chronic exposure to type I interferons. $J$ Exp Med. 2014;211(2):245-62.

24. Essers MA, Offner S, Blanco-Bose WE, et al. IFNalpha activates dormant haematopoietic stem cells in vivo. Nature. 2009;458(7240):904-8.

25. Walter D, Lier A, Geiselhart A, et al. Exit from dormancy provokes DNA-damageinduced attrition in haematopoietic stem cells. Nature. 2015;520(7548):549-552.

26. Nam AS, Kim KT, Chaligne R, et al. Somatic mutations and cell identity linked by Genotyping of Transcriptomes. Nature. 2019;

27. Ianotto J-C, Chauveau A, Boyer-Perrard F, et al. Benefits and pitfalls of pegylated interferon- $\alpha 2$ a therapy in patients with myeloproliferative neoplasm-associated myelofibrosis: a French Intergroup of Myeloproliferative neoplasms (FIM) study. Haematologica. 2018;103(3):438446.

28. Cassinat B, Verger E, Kiladjian J-J. Interferon alfa therapy in CALR-mutated essential thrombocythemia. N Engl J Med. 2014;371(2):188-189.

29. Silver RT, Barel AC, Lascu E, et al. The effect of initial molecular profile on response to recombinant interferon- $\alpha(\mathrm{rIFN} \alpha)$ treatment in early myelofibrosis. Cancer. 2017;123(14):2680 2687.

30. Yamane A, Nakamura T, Suzuki H, et al. Interferon-alpha 2b-induced thrombocytopenia is caused by inhibition of platelet production but not proliferation and endomitosis in human megakaryocytes. Blood. 2008;112(3):542-550.

31. Hasan S, Cassinat B, Droin N, et al. Use of the 46/1 haplotype to model JAK2(V617F) clonal architecture in PV patients: clonal evolution and impact of IFNalpha treatment. Leukemia. 2014;28(2):460-3.

32. Jäger R, Gisslinger H, Fuchs E, et al. Germline Genetic Factors Influence Outcome of Interferon Alpha Therapy in Polycythemia Vera. Blood. 2020; 
33. Pedersen RK, Andersen M, Knudsen TA, et al. Data-driven analysis of JAK2 V617F kinetics during interferon-alpha2 treatment of patients with polycythemia vera and related neoplasms. Cancer Med. 2020;9(6):2039-2051.

34. King KY, Matatall KA, Shen C-C, et al. Comparative long-term effects of interferon $\alpha$ and hydroxyurea on human hematopoietic progenitor cells. Experimental Hematology. 2015;43(10):912-918.e2.

35. Austin RJ, Straube J, Bruedigam C, et al. Distinct effects of ruxolitinib and interferonalpha on murine JAK2V617F myeloproliferative neoplasm hematopoietic stem cell populations. Leukemia. 2020;34(4):1075-1089.

36. Rao TN, Hansen N, Stetka J, et al. JAK2-V617F and interferon- $\alpha$ induce megakaryocytebiased stem cells characterized by decreased long-term functionality. Blood. 2021;

37. Hasan S, Lacout C, Marty C, et al. JAK2V617F expression in mice amplifies early hematopoietic cells and gives them a competitive advantage that is hampered by IFNalpha. Blood. 2013;122(8):1464-77.

38. Tong J, Sun T, Ma S, et al. Hematopoietic Stem Cell Heterogeneity Is Linked to the Initiation and Therapeutic Response of Myeloproliferative Neoplasms. Cell Stem Cell. 2021;S1934590921000187.

39. Dagher T, Maslah N, Edmond V, et al. JAK2V617F myeloproliferative neoplasm eradication by a novel interferon/arsenic therapy involves PML. J Exp Med. 2021;218(2):.

40. Liu P, Zhao L, Loos F, et al. Immunosuppression by Mutated Calreticulin Released from Malignant Cells. Molecular Cell. 2020;77(4):748-760.e9.

41. Benlabiod C, Cacemiro M da C, Nédélec A, et al. Calreticulin del52 and ins5 knock-in mice recapitulate different myeloproliferative phenotypes observed in patients with MPN. Nat Commun. 2020;11(1):4886.

\section{Figure legends}

\section{Figure 1. Inclusion criteria for various steps of analyses and IFN $\alpha$ dosage}

(A) Strategy of analysis and inclusion. Experimental observations were analyzed from progenitor and mature cells of the 48 patients of the cohort. We then excluded patients who had less than two data points (in progenitors and after the start of the therapy) for mathematical model calibration because there is no rationale to try to fit only two data points. To rigorously statistically analyze how IFN $\alpha$ dosages differently impacts molecular response according to the mutation type and zygosity in HSC, we still had to exclude patients with no more than five progenitor type measurements from the start of the therapy for $J A K 2^{V 617 F}$ patient. No $C A L R^{m}$ patient was excluded because the model was less complex. The number in parenthesis corresponds to the percentage of data used for the analyses. (B) To study the effect of IFN $\alpha$ on HSC depending on the zygosity, it was necessary to exclude $J A K 2^{\mathrm{V} 617 \mathrm{~F}}$ patients whose clones exhibited too low clonal fraction $(\mathrm{CF})$ 
overtime. This analysis was not performed for $C A L R^{m}$ MPN since only 2 out of 12 patients had homozygous mutated cells. For our statistical analyses, a $J A K 2^{\mathrm{V} 617 \mathrm{~F}}$ patient was labeled as carrying homozygous (respectively heterozygous) subclones when $\mathrm{CF}>7 \%$ of homozygous (respectively heterozygous) progenitors were identified from at least one of the collected samples. Following this definition, some patients (8) could be considered as carrying both heterozygous and homozygous subclones. Using this criterium, 17 patients carry heterozygous subclones and 10 patients carry homozygous subclones. (C) Averaged IFN $\alpha$ dosage received overtime by the 48 patients. Grey lines indicate the individual dosage and the blue line indicate the mean dosage received by the 48 patients. The shaded areas surrounding the curve represent the standard error of the mean.

\section{Figure 2. Characterization of the IFNa treated MPN patient cohort.}

(A) Distribution of MPN diseases. (B) Distribution of MPN driver mutations. (C) Diseases and the molecular profile determined using an NGS myeloid panel of 77 genes of the first sample collected from the 48 patients in the studied cohort. P45 presented two diseases, ET/PV, based on its molecular profile $\left(J A K 2^{\mathrm{V} 617 \mathrm{~F}}\right.$ and $\left.C A L R^{m}\right)$ and its high platelets count and hematocrit (75\%) (D) Percent of hematological response, non-response or intolerance among patients with $J A K 2^{\mathrm{V} 617 \mathrm{~F}}$ (left) or $C A L R^{m}$ (right) MPN.

Figure 3: Hematopoietic progenitors are targeted differently according to the driver mutation type or zygosity and the IFNa dosage.

(A) Effect of IFN $\alpha$ in different hematopoietic compartments during the clinical survey of the 48 patients. Graph lines indicate the VAF calculated in $\mathrm{CD} 34^{+}$progenitors (i, ii), and measured in granulocytes (iii, iv) for $C A L R^{m}$ and $M P L^{m}$ patients (i, iii) and $J A K 2^{V 617 F}$ patients (ii, iv). Thin lines represent data from each patient harboring $J A K 2^{\mathrm{V} 617 \mathrm{~F}}$ (dotted blue), $C A L R^{m}$ (dotted orange) or $M P L^{m}$ (green). Thick curves are smoothed averages (floating averages over \pm 100 days) from the 32 $J A K 2^{\mathrm{V} 617 \mathrm{~F}}$ (blue) or $14 C A L R^{m}$ (orange) patient data. The surrounding shaded areas represent the 
standard error of the mean. P-values were calculated between $C A L R^{m}$ and $J A K 2^{\mathrm{V} 617 \mathrm{~F}}$ data. Within the first 300 days, there was no significant difference between $C A L R^{m}$ and $J A K 2^{\mathrm{V} 617 \mathrm{~F}}$ patient VAF. Significant differences between $C A L R^{m}$ and $J A K 2^{\mathrm{V} 617 \mathrm{~F}}$ cases were observed starting from 600 days of treatment in the progenitor compartment using a Mann and Whitney $U$ test $(\mathrm{P}<0.0005)$. Less difference between $C A L R^{m}$ and $J A K 2^{\mathrm{V} 617 \mathrm{~F}}$ VAF was observed in mature cells $(\mathrm{P}<0.025$ after 650 days).

(B) Effect of IFN $\alpha$ according to driver mutation type or zygosity and the IFN $\alpha$ dosage during the clinical survey. The VAF were computed by pooling the data from each of the three progenitor compartments for (i) patients with $C A L R^{m}$ MPN treated with IFNa at high dosages (HD, >78 $\mu \mathrm{g} /$ week on average) or low dosages (LD, $<78 \mu \mathrm{g} /$ week), (ii) patients with $J A K 2^{\mathrm{V} 617 \mathrm{~F}} \mathrm{MPN}$ treated with IFN $\alpha$ at high dosages $\left(>96.5 \mu \mathrm{g} /\right.$ week) or low dosages $(<96.5 \mu \mathrm{g} /$ week $)$ and (iii) $J A K 2^{\mathrm{V} 617 \mathrm{~F}}$ heterozygous or homozygous progenitors independently of the dosages. Each thin line represents data from a single patient. Thick curves are smoothed averages (floating averages over \pm 100 days) from the $J A K 2^{\mathrm{V} 617 \mathrm{~F}}$ (blue) or $C A L R^{m}$ (orange) patient data. The shaded areas surrounding the curve represent standard error of the mean. Differences were calculated between heterozygous and homozygous $J A K 2^{\mathrm{V} 617 \mathrm{~F}}$ progenitors after 600 days of treatment (Mann and Whitney $\mathrm{U}$ test, $\mathrm{P}<0.03$ ) and were significant after 1,000 days of treatment (Mann and Whitney $\mathrm{U}$ test, $\mathrm{P}<0.003$ ).

\section{Figure 4: Mathematical model and inferred dynamics of $J A K 2^{\mathrm{V} 617 \mathrm{~F}}, C A L R^{m}$ and $M P L^{m}$ cells.}

(A) Design of the mathematical model. Mature and fully differentiated cells no longer divide and die at a rate $\delta_{\mathrm{m}}$. We modeled progenitor cells as originating from an active HSC that divide and encounter several divisions (modeled by the parameter $\kappa_{\mathrm{i}}$ ). Progenitors exit their compartment at the differentiation rate $\delta_{\mathrm{i}}$ and proliferate (modeled by the parameter $\kappa_{\mathrm{m}}$ ) before entering the mature compartment. We also introduced two stem cell compartments depending on whether the HSC is considered active or inactive (quiescent), parameters $\gamma$ and $\beta$ model the exchanges between these two compartments. We assumed that the active HSC might be recruited to differentiate at a rate $\alpha$ to 
contribute to hematopoiesis. Parameter $\Delta$ models the propensity of the stem cell pool to be depleted (if $\Delta<0$ ) or to expand (if $\Delta>0$ ). (B) Examples of dynamics of inferred mutated progenitor, HSC (Clonal Fractions, CF) and mutated mature cells (VAF) are presented. Dynamics focusing on (i) homozygous $J A K 2^{V 617 F}$ cells for three patients, (ii) heterozygous $J A K 2^{V 617 F}$ cells from two patients, (iii) heterozygous $C A L R^{m}$ cells from two patients and (iv) heterozygous $M P L^{m}$ cells from a patient. The dots, square and triangles are the experimental data values. The curves are median values determined from the mathematical model. The purple line represents the inferred dynamics of mutated HSC (overlaid with the heterozygous progenitor CF for $C A L R^{m}$ cases). The shaded areas surrounding each curve represent $95 \%$ confidence intervals. To note that, when comparing mature cells dynamics to heterozygous progenitor dynamics, we have to keep in mind that the VAF in progenitor cells would be half the $\mathrm{CF}$.

Figure 5: HSC are targeted differently according to driver mutation type and zygosity and the

\section{IFN $\alpha$ dosages}

Molecular stem cell response factor ( $\mathrm{R}$ factor) was predicted at the end of the survey $(3,000$ days) for (i) heterozygous $C A L R^{m}$ HSC in patients treated with high versus low IFN $\alpha$ dosages, (ii) heterozygous type 1 versus heterozygous type $2 C A L R^{m}$ HSC (iii) heterozygous versus homozygous $J A K 2^{\mathrm{V} 617 \mathrm{~F}} \mathrm{HSC}$ (iv) heterozygous $J A K 2^{\mathrm{V} 617 \mathrm{~F}} \mathrm{HSC}$ in patients treated with high versus low IFNa dosages, (v) homozygous $J A K 2^{\mathrm{V} 617 \mathrm{~F}} \mathrm{HSC}$ in patients treated with high versus low IFNa dosages, (vi) global $J A K 2^{\mathrm{V} 617 \mathrm{~F}} \mathrm{HSC}$ in patients treated with high versus low IFN $\alpha$ dosages. The $\mathrm{R}$ factor is defined as the ratio (median value) between the inferred mutated HSC proportion after a given time of treatment ( $\mathrm{t}=3,000$ days) over the proportion of mutated HSC at the initial time. Depending on the context, it refers to heterozygous or homozygous Clonal Fraction (CF) or VAF. The dash lines indicate $\mathrm{R}=1$ for no response, $\mathrm{R}>1$ for a negative response and $\mathrm{R}<1$ for a positive response. $\mathrm{R}<0.5$ corresponds to a partial molecular response (PMR), and $\mathrm{R} \sim 0$ corresponds to a complete molecular response (CMR). The solid lines correspond to $\mathrm{R}$ median. $\mathrm{R}$ significantly differs between 
heterozygous $C A L R^{m} \mathrm{HSC}$ with low versus high IFNa dosages (Mann-Whitney U test, $\mathrm{P}=0.0087$ ) and between type $1 C A L R^{m}$ and type $2 C A L R^{m}$ (Mann-Whitney $\mathrm{U}$ test, $\mathrm{P}=0.0162$ ). $\mathrm{R}$ significantly differs between heterozygous versus homozygous JAK2 $2^{\mathrm{V} 617 \mathrm{~F}}$ HSC (Mann-Whitney U test, $\mathrm{P}=0.0047)$. $\mathrm{R}$ tends to differ between heterozygous $J A K 2^{\mathrm{V} 617 \mathrm{~F}} \mathrm{HSC}$ treated with high vs. low IFN $\alpha$ dosages (Mann-Whitney $\mathrm{U}$ test, $\mathrm{P}=0.0745$ ). $\mathrm{R}$ significantly differs in the global $J A K 2^{\mathrm{V} 617 \mathrm{~F}} \mathrm{VAF}$ in HSC between treated with high dosages and low dosages IFN $\alpha$ (Mann-Whitney U test, $\mathrm{P}=0.0288$ ). For each patient, we computed an average of received IFN $\alpha$ dosages over the first 450 days of treatment. High dosages versus low dosages are defined according to the median dosage of the groups of considered patients. The threshold is automatically computed to compare two subgroups of patients of the same size. The dosage thresholds of IFN $\alpha$ are $78 \mu \mathrm{g} /$ week for heterozygous $C A L R^{m}$ HSC, $96.5 \mu \mathrm{g} /$ week for $J A K 2^{V 617 F}$ HSC, $96 \mu \mathrm{g} /$ week for heterozygous $J A K 2^{V F 617 F}$ and 108 $\mu \mathrm{g} /$ week for homozygous $J A K 2^{V 617 F}$ HSC. Statistical differences were calculated using a Mann Whitney $\mathrm{U}$ test; $* \mathrm{P}<0.05, * * \mathrm{P}<0.01)$.

\section{Figure 6: IFNa differentially impacts on $J A K 2^{\mathrm{V} 617 \mathrm{~F}}$ and $C A L R^{m} \mathrm{HSC}$ homeostasis}

(A) Graphs indicate the means values (solid lines) of the estimated parameters calculated using the mathematic model. (i) $\Delta^{*}$ parameters were calculated in heterozygous and homozygous $J A K 2^{\mathrm{V} 617 \mathrm{~F}}$ HSC and heterozygous $C A L R^{m}$ HSC. $\Delta^{*}{ }_{\text {het }}$ significantly differs in patients with $C A L R^{m}$ MPN versus those having $J A K 2^{\mathrm{V} 617 \mathrm{~F}}$ MPN (Mann-Whitney U test, $\left.\mathrm{P}=0.0031\right) . \Delta^{*}{ }_{\text {het }}$ in patients with $C A L R^{m} \mathrm{MPN}$ is significantly different from $\Delta^{*}$ hom of those having $J A K 2^{\mathrm{V} 617 \mathrm{~F}}$ MPN (Mann-Whitney U test, $\mathrm{P}<0.0001)$. The dotted lines indicate $\Delta^{*}=0 . \Delta^{*}>0$ corresponds to an expansion and $\Delta^{*}<0$ corresponds to a depletion of the stem compartment. (ii) $\Delta^{*}$ het parameters were calculated in type 1 and type 2 $C A L R^{m}$ HSC. $\Delta^{*}$ het significantly differs in patients with type $1 C A L R^{m}$ MPN versus those type 2 $C A L R^{m}$ MPN (Mann-Whitney $\mathrm{U}$ test, $\mathrm{P}=0.004$ ). (iii) Inverse ratios of the $\gamma^{*}$ parameter was calculated in heterozygous versus homozygous $J A K 2^{\mathrm{V} 617 \mathrm{~F}} \mathrm{HSC}$. The $1 / \gamma^{*}$ value can be seen as a relative time spent by cells in the inactive compartment of our model. The $1 / \gamma^{*}$ significantly differs 
in heterozygous versus homozygous $J A K 2^{\mathrm{V} 617 \mathrm{~F}}$ HSC (Mann-Whitney U test, $\mathrm{P}=0.027$ ); (B) Proposed mechanism of IFN $\alpha$ in $J A K 2^{\mathrm{V} 617 \mathrm{~F}}$ and $C A L R^{m} \mathrm{HSC}$. 

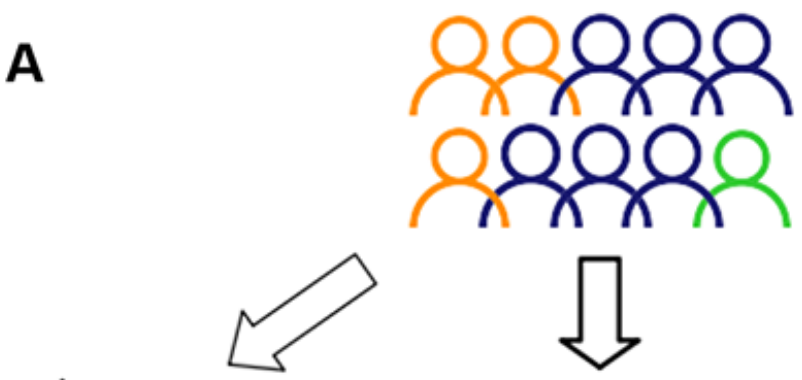

80

$\leq 2$ progenitor

measures

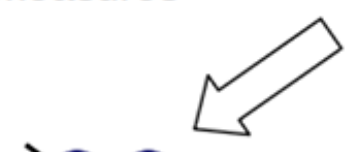

180

Risk of overfitting $\sqrt{1}$
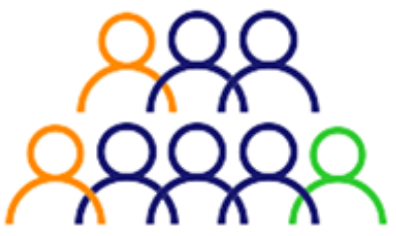

$\sqrt{1}$

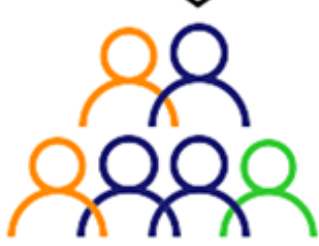

Analyzes of experimental observations:

48 patients (32 JAK2 $2^{\mathrm{V} 617 \mathrm{~F}}, 14 \mathrm{CALR} \mathrm{R}^{m}, 2 M P L^{m}$ ) 409 VAF measurements in mature cells

Mutational status of 84,845 progenitor colonies

Calibration of the mathematical model: 40 patients (27 JAK2 $\left.2^{\mathrm{V} 617 \mathrm{~F}}, 12 \mathrm{CALR}^{m}, 1 \mathrm{MPL}^{\mathrm{m}}\right)$ 380 VAF measurements in mature cells (93\%) Mutational status of 79,053 progenitor colonies (93\%)

\section{Quantitative comparison according to mutation} type \& dose:

33 patients (20 JAK2 $2^{\mathrm{V} 617 \mathrm{~F}}, 12 \mathrm{CALR}^{m}, 1 \mathrm{MPL}^{m}$ )

351 VAF measurements in mature cells (86\%) Mutational status of 73,808 progenitor colonies (87\%)

B

C

\begin{tabular}{|c|c|c|c|}
\hline \multicolumn{2}{|c|}{} & \multicolumn{2}{|c|}{$\begin{array}{c}\text { Patients carrying } \\
\text { homozygous subclones }\end{array}$} \\
\cline { 2 - 4 } $\begin{array}{c}\text { Study of zygosity for } \\
20 \text { JAK2 }\end{array}$ 617F patients & $\begin{array}{c}\text { CF }>7 \% \text { for } \\
\text { at least 1 } \\
\text { measure }\end{array}$ & $\begin{array}{c}\text { CF }<7 \% \text { for } \\
\text { all measures }\end{array}$ \\
\hline \multirow{2}{*}{$\begin{array}{c}\text { Patients } \\
\text { carrying } \\
\text { heterozygous } \\
\text { subclones }\end{array}$} & $\begin{array}{c}\text { CF }>7 \% \text { for } \\
\text { at least 1 } \\
\text { measure }\end{array}$ & 8 & 9 \\
\cline { 2 - 4 } & $\begin{array}{c}\text { CF }<7 \% \text { for } \\
\text { all measures }\end{array}$ & 2 & 1 \\
\hline
\end{tabular}

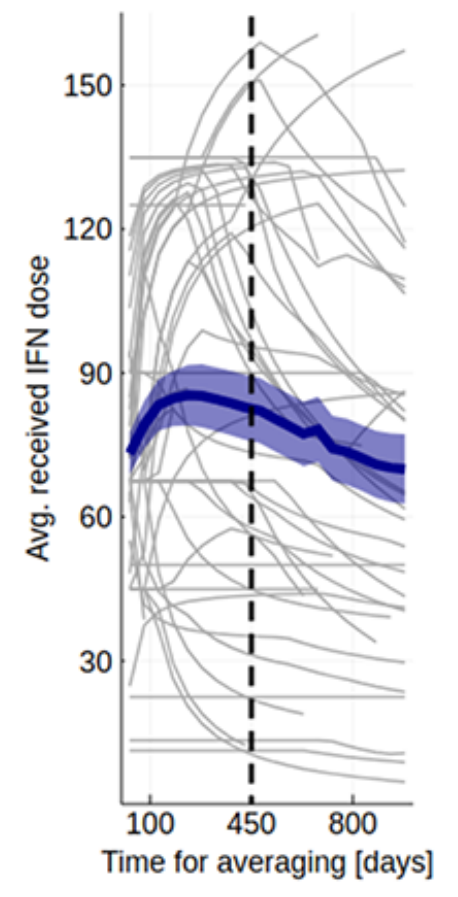

individual Dosage

Mean dosage over all patients 


\section{A MPN distribution B Driver mutations}
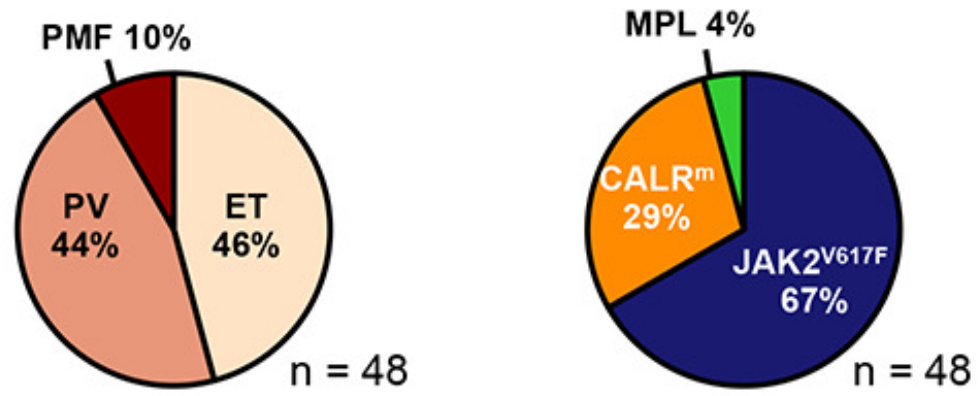

C

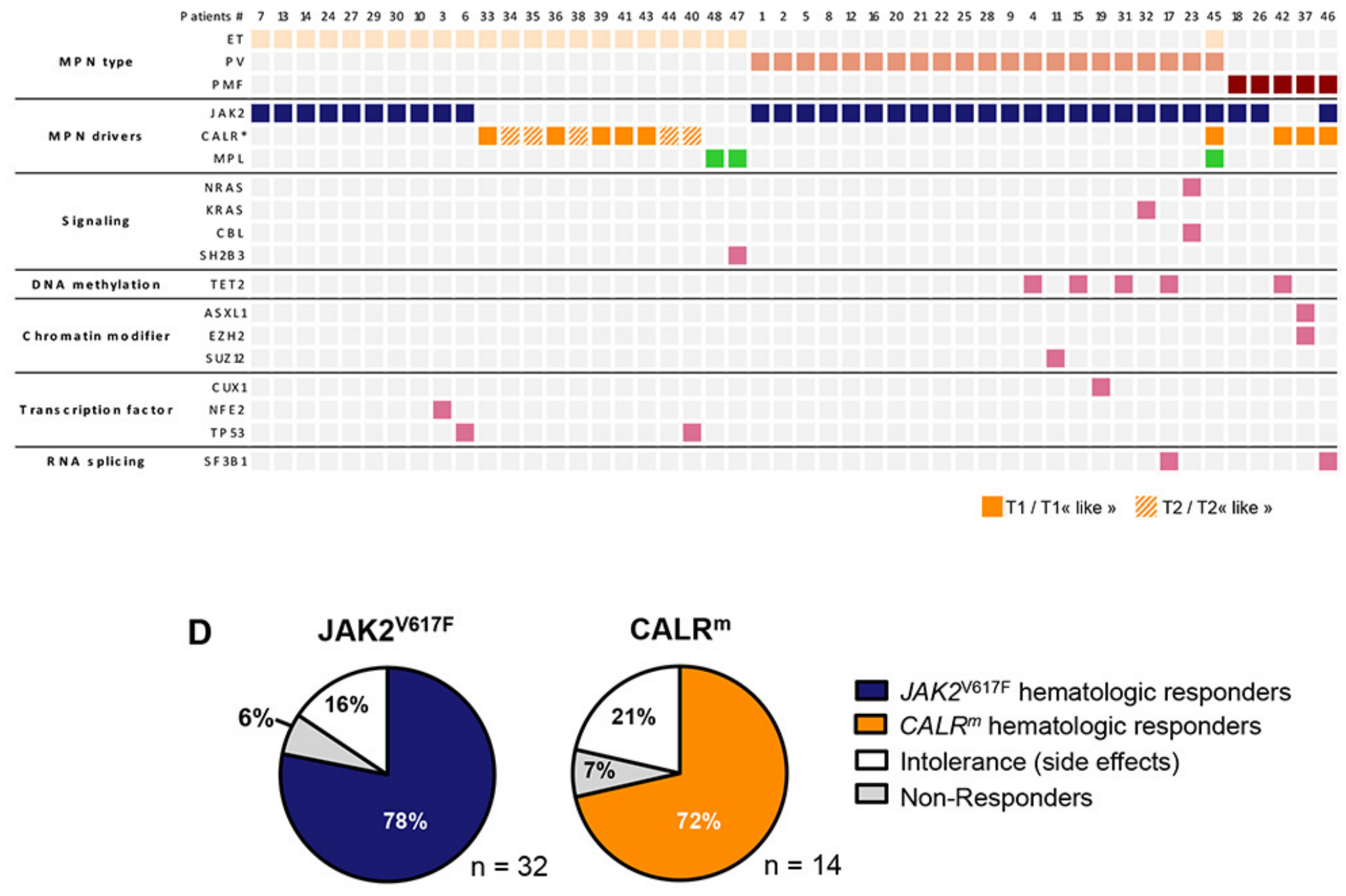

Mosca, Hermange, Tisserand, Noble et al., Figure 2 

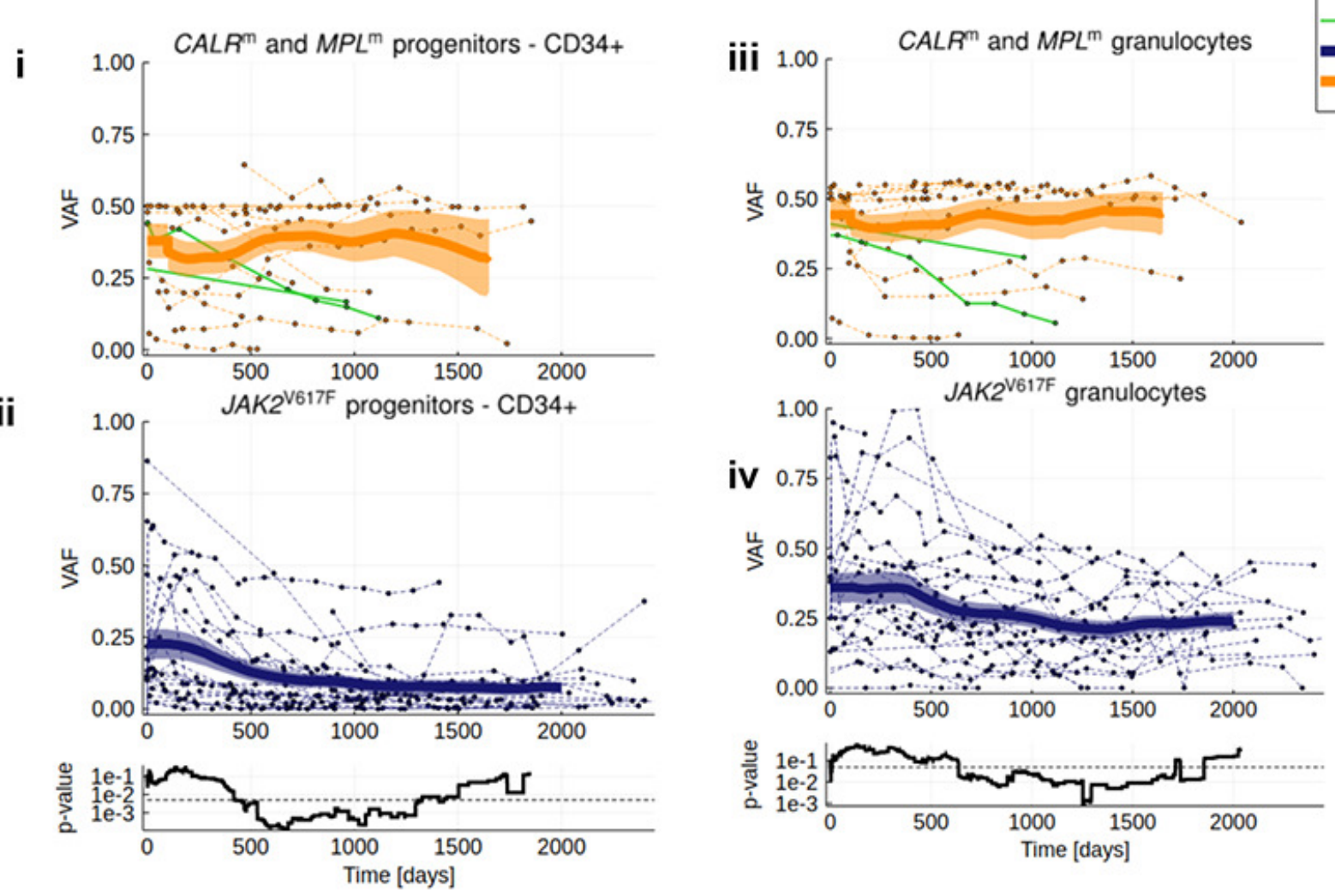

B
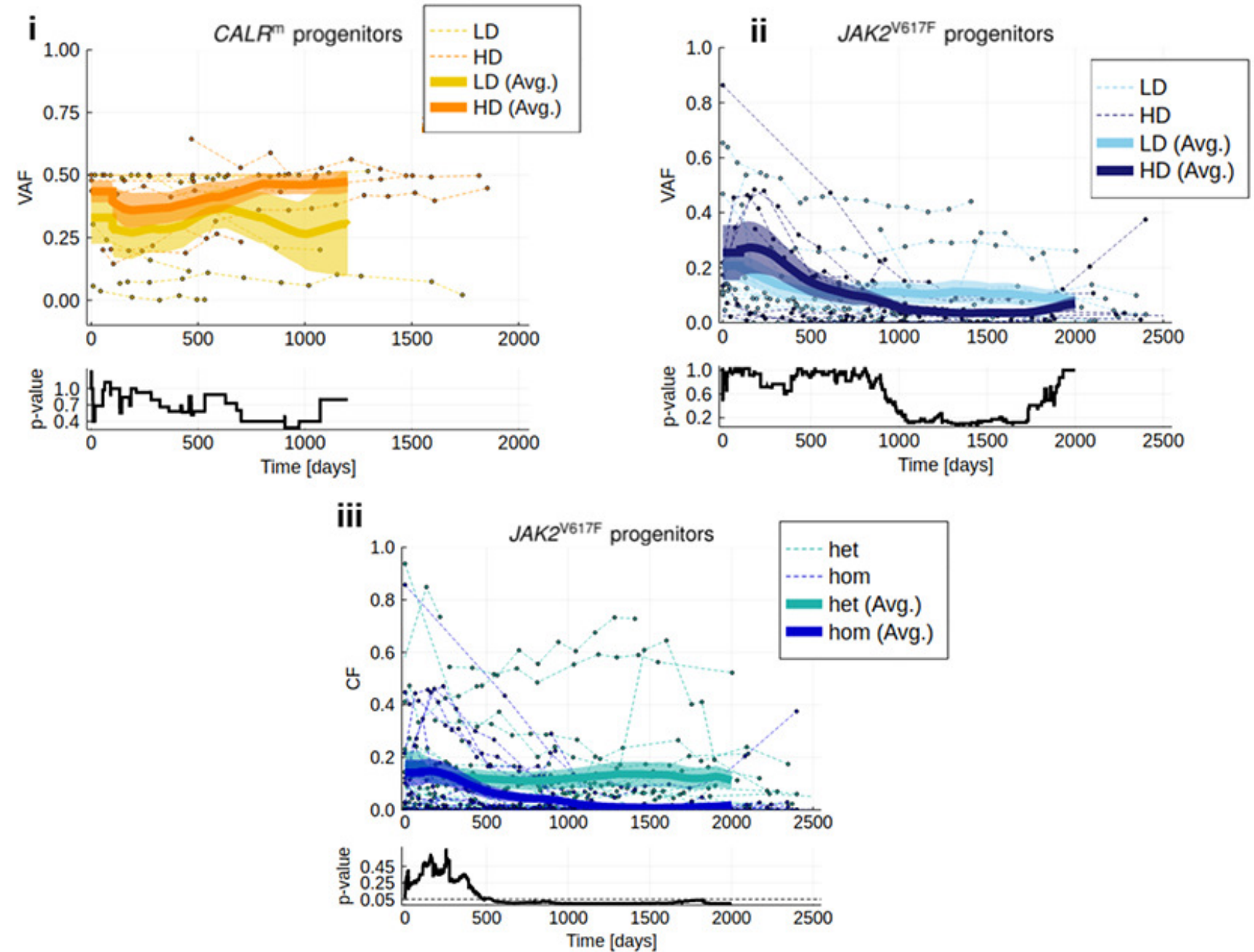

Mosca, Hermange, Tisserand, Noble et al., Figure 3 
A
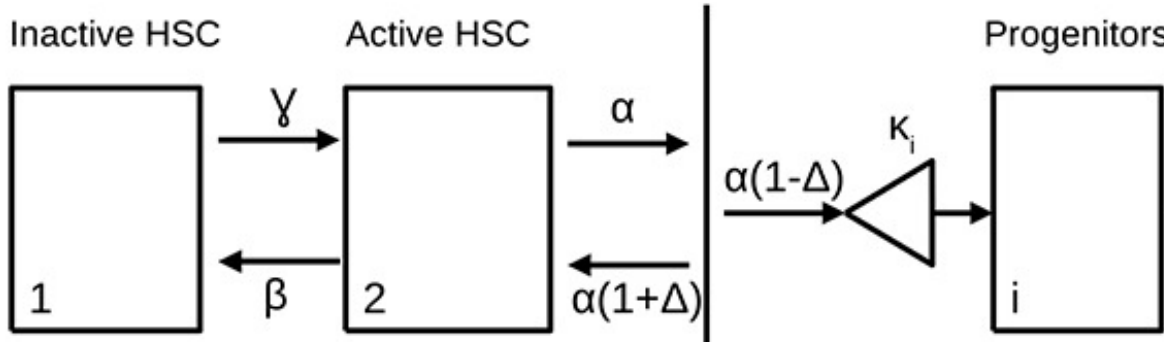

Mature cells
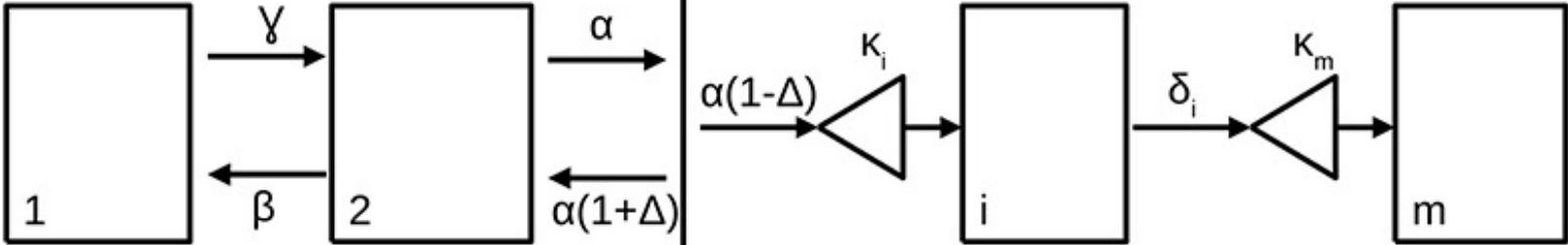

B
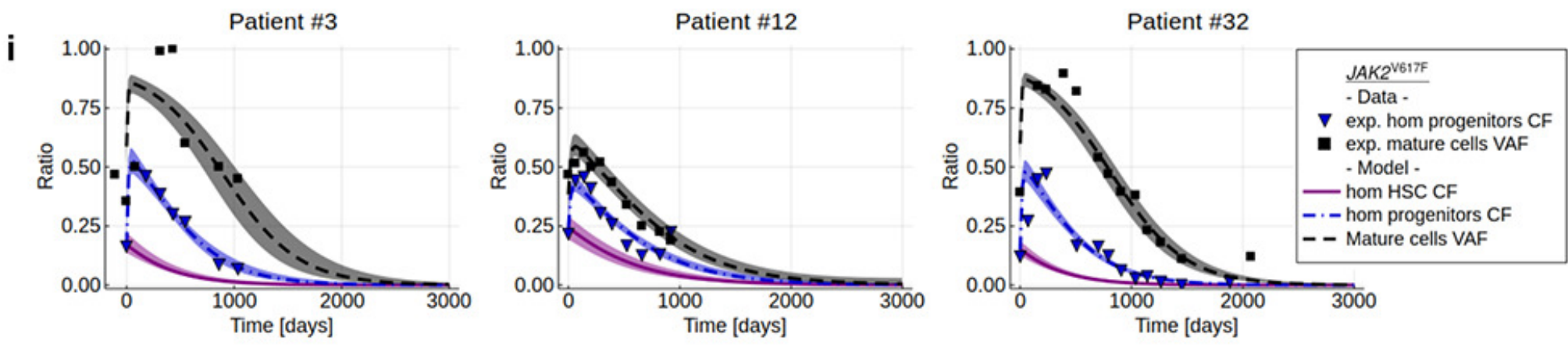

ii

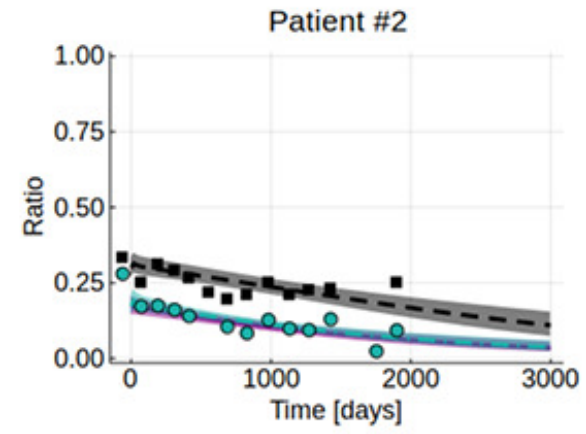

iii

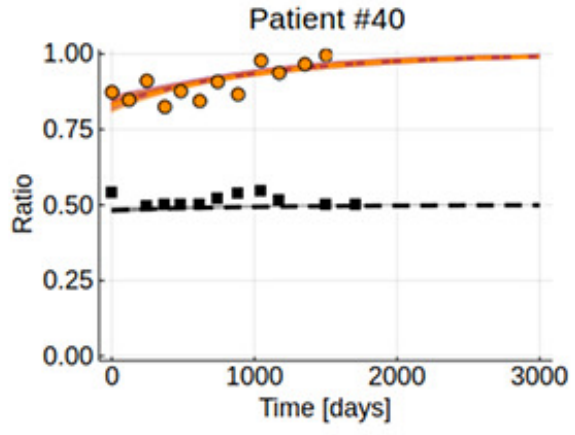

iv

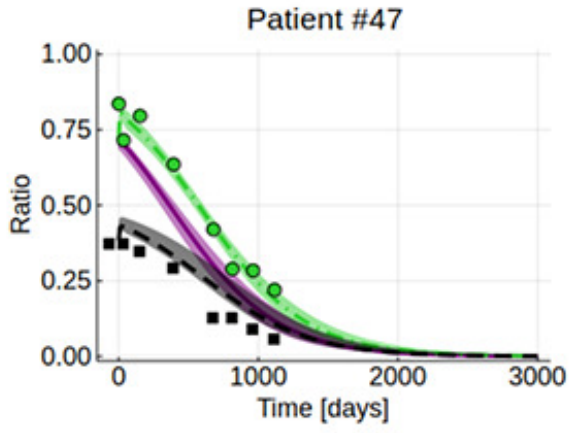

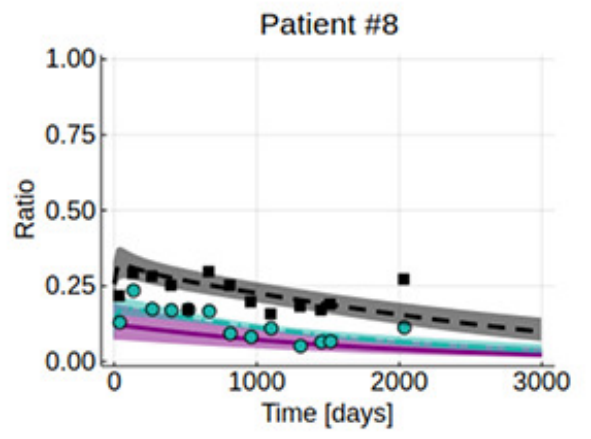

\begin{tabular}{|c|c|}
\hline $\begin{array}{c}0 \\
\mathbf{0} \\
-\cdot- \\
--\end{array}$ & $\begin{array}{l}\text { JAK2 } 2^{\mathrm{V} 17 \mathrm{~F}} \\
\text { - Data - } \\
\text { exp. het progenitors CF } \\
\text { exp. mature cells VAF } \\
\text { - Model - } \\
\text { - het HSC CF } \\
\text { - het progenitors CF } \\
\text { Mature cells VAF }\end{array}$ \\
\hline
\end{tabular}

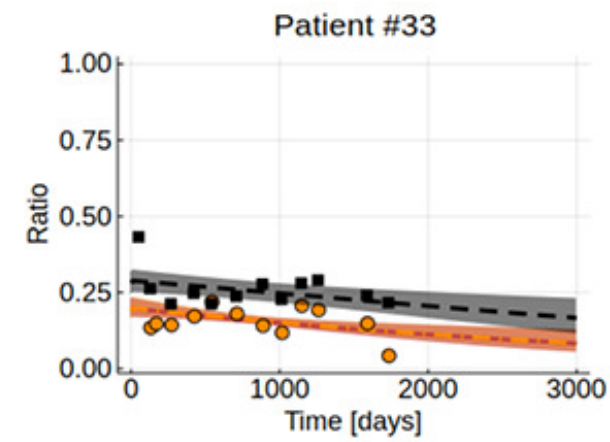

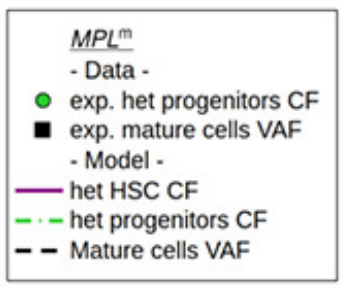



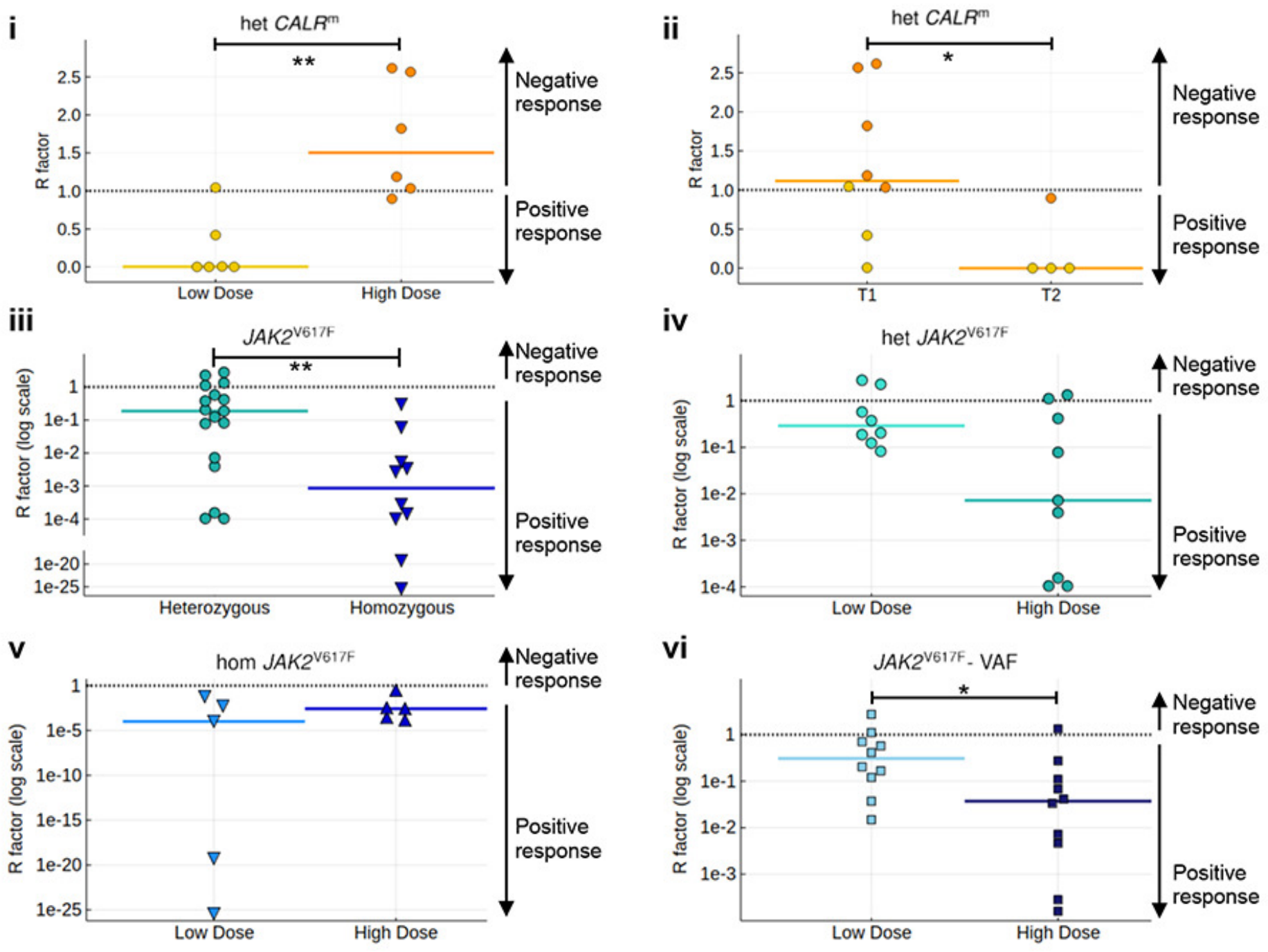



B

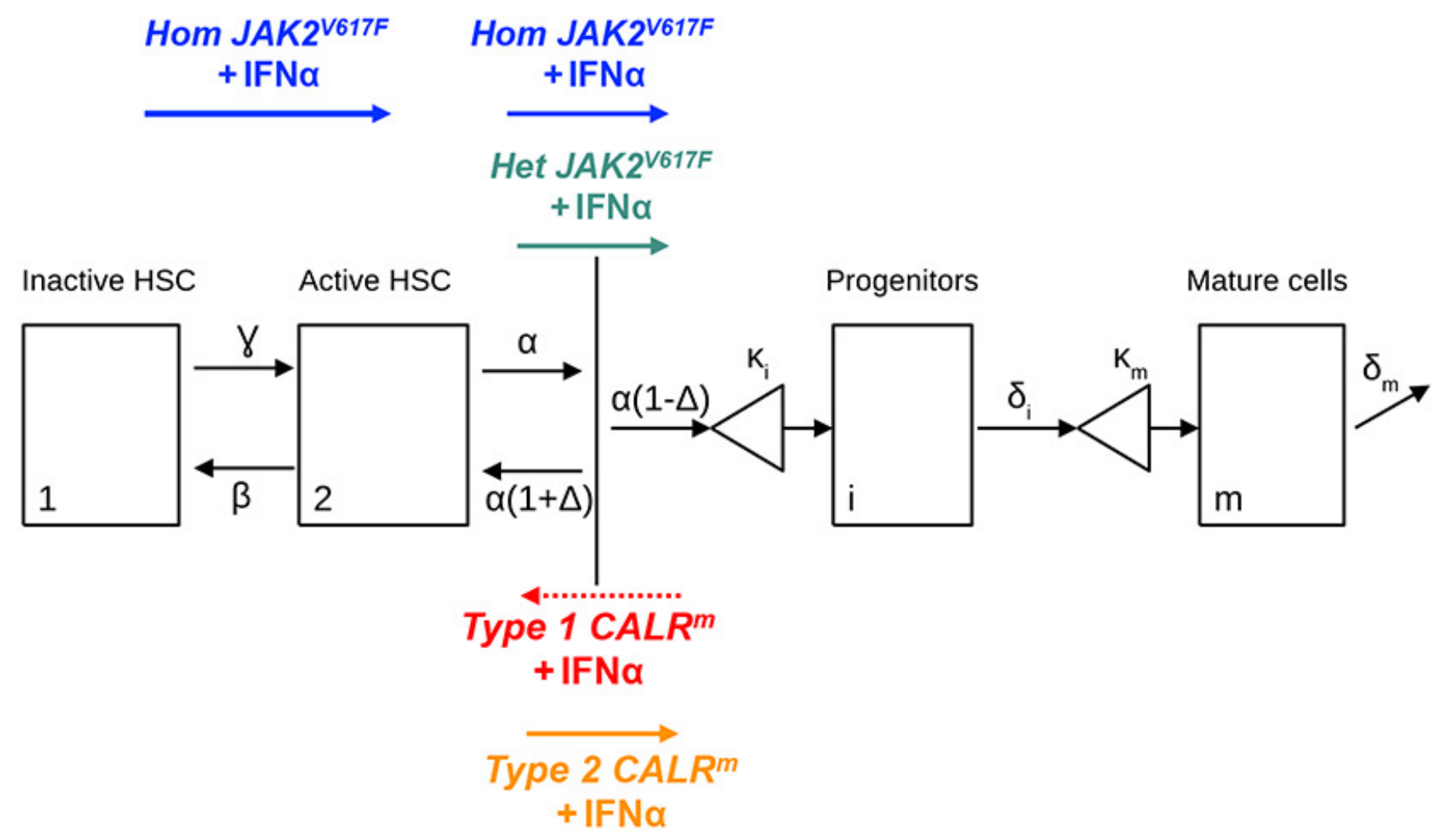

